\title{
Canadian Mortality in Perspective: A Comparison with the United States and other Developed Countries
}

\author{
Robert Bourbeau \\ Department of Demography and \\ Interuniversity Center for Demographic Studies \\ Université de Montréal \\ Montréal, Québec, Canada
}

\begin{abstract}
:
The purposes of this paper is to compare mortality patterns in Canada to the United States and to other industrialised countries to give support to the existence of a "North American Mortality Pattern" (NAMP), and to try to explain this pattern in the context of the specific features of Canadian society. Using data from the WHO mortality database for total and cause-specific mortality, we applied a decomposition method to explain the changes in mortality rate ratios during the 1950-1995 period. Our findings show that Canada has experienced a general increase of its mortality rate ratios compared to other developed countries. There is no evidence that the NAMP fits for Canada. In fact, Canadian mortality below age 65 is quite comparable to mortality in other developed countries. However there is a contrasting low mortality level for the oldest-old $(80+)$.
\end{abstract}

Key Words: Mortality by age and cause, Canada, international comparisons. 
Robert Bourbeau

\section{Résumé:}

Cet article a pour but de comparer le profil de la mortalité canadienne à celui des États-Unis et de plusieurs pays développés afin de vérifier l'existence d'un "profil nord américain de la mortalité », et de tenter de l'expliquer dans le contexte particulier de la société canadienne. Nous avons utilisé les données de la banque de l'OMS sur la mortalité selon l'âge et la cause de décès pour tenter d'interpréter, à l'aide d'un modèle de décomposition, les changements relatifs de la mortalité canadienne au cours de la période 1950 à 1995 . Le Canada a connu une détérioration générale de ses taux de mortalité relativement aux autres pays développés. Le Canada présente un profil de mortalité distinct des États-Unis, sauf pour une caractéristique commune, la plus faible mortalité aux grands âges (80 ans et plus.)

Mots-clés: Mortalité selon l'âge et la cause du décès, Canada, comparaisons internationales.

\section{Introduction}

There has been a huge reduction in the level of Canadian mortality during the twentieth century (Bourbeau, Légaré and Émond, 1997; Goss, Wade and Bell, 1998), but major changes also occurred in the age pattern of total and cause-specific mortality (Nagnur and Nadrodski, 1990; Bah and Rajulton, 1991). This modification is related to the fact that some groups have benefited more than others from the major breakthroughs in medical research, from progress in economic and social development, and from the amelioration in standards of living. Infant and child mortality rates have decreased more rapidly than for the other age groups during a long period in the twentieth century (Bourbeau and Légaré, 2000). Female mortality has also declined more than male, and subgroups with higher levels of education and income showed a greater decrease in their level of mortality (Wigle and Mao, 1980; Wilkins and Adams, 1983; Wilkins, Adams and Brancker, 1989; Choinière, 1993, Wilkins, 1995, Nault, 1997).

The age pattern of Canadian mortality has changed over time, but how does it compare to the patterns in other developed countries, especially in the United States? The question is relevant since some researchers have suggested the existence of an unusual age mortality pattern for the United States (Manton and Vaupel, 1995, Preston et al. 1996, Wilmoth, 1998) and that this pattern would fit for Canada (Himes, 1994; Bennett and Olshansky, 1996). This so called North American mortality profile is characterised by relatively high death rates below age 65 and relatively low death rates above age 80, when compared to other developed countries. 
Canadian Mortality in Perspective:

A Comparison with the United States and other Developed Countries

The first purpose of the paper is to compare mortality patterns in Canada to the United States and other industrialised countries to test the existence of a North American mortality pattern. The second purpose is to try to explain this pattern in the context of the specific features of Canadian society.

The comparison with the United States is interesting because this country experienced a very unusual evolution in age-specific mortality rates since 1950. In a recent paper, Wilmoth (1998) has suggested a sound method to illustrate the unique age pattern of American mortality and to show how it has changed between the 1950 s and the early 1990s. In the early fifties, American mortality under age 40 was below the average when compared to 20 other developed countries. But there has been a significant deterioration in the American relative position over time, and at the beginning of the 1990s the United States nearly ranked last among 23 other developed countries for all age groups from 0 to 64 years old. However mortality rates for the age group 65-79 remained near the average, and oldest-old mortality $(80+)$ is still one the lowest in the world. According to the WHO and UN data on mortality, only four developed countries had lower death rates at ages $80+$ in 1990: Iceland, Japan, Canada and France. In this paper, the same approach is used for Canada, leading to a comparative study with the United States.

Some arguments have been suggested to explain the unique age pattern of American mortality: data quality (exaggeration of age at death) (Coale and Kisker, 1986, 1990; Elo and Preston, 1994; Kannisto et al., 1994), population undercoverage for young age groups, excessive levels of mortality for adolescents and young adults due to accidents and violence, adverse selection (Manton and Vaupel, 1995; Vaupel, Manton and Stallard, 1979), socioeconomic inequalities; and the existence of a universal medical care for the elderly (Himes, 1994; Bennett and Olshansky, 1996; Wilmoth, 1998). In this paper, these hypotheses are revisited for Canadian mortality.

\section{Overview of the Trends in Canadian Mortality}

In this section, an overview of the trends in the main indicators of Canadian mortality is presented. It shows data on life expectancy at birth, infant mortality, and age-specific mortality rates, with some brief comparisons with the United States.

According to the estimations made by Bourbeau et al. (1997), mortality in Canada has been declining for a long period, at least since the beginning of the nineteenth century. Life expectancy at birth was estimated at about 39 years at the time, while it increased to about 57 years in 1921.

When the system for registering vital statistics began in the 1920s in Canada (1921 in Canada except Quebec and 1926 in Quebec), data on deaths became more reliable. By 1931, life expectancy at birth reached 62.1 for women and 
Robert Bourbeau

60.0 years for men; it increased steadily during the twentieth century as shown in Figure 1.

With a life expectancy at birth of nearly 79 years $(81.5$ for women and 75.7 for men) in 1996, Canada is among the leading countries in the world in terms of health and longevity. Canada ranked fourth in life expectancy for men after Japan, Sweden, and Iceland and sixth for women after Japan, Sweden, France, Spain, and Switzerland (Statistics Canada, 1998).

The main features of Canadian mortality during the twentieth century have been well documented for the period 1931-1981(Nagnur and Nagrodski, 1990; Bah and Rajulton, 1991); updating the data for the period 1921-1996, we find the following results:

- Infant mortality decreased by $93 \%$ for males and for females

- Life expectancy at birth increased by 17 years for males and 21 years for females

- The difference between male and female life expectancy increased from 2 years in 1921 to 7.2 years in 1981 and then began to decrease, to reach 5.8 years in 1996.

- A large increase in the number of survivors at older ages

- An increasing rectangularization of the survival curve

- Changes in the causes of death, from predominantly diseases of underdevelopment to predominantly diseases of development.

\section{Life Expectancy at Birth, Canada and the United States, 1901-1996}

The United States has a lower life expectancy at birth than Canada according to the 1996 data: 73.1 for American males (74.3 for white males only) and 79.1 for American females (79.7 for white females).

Figure 1 shows that at the beginning of the twentieth century, life expectancy at birth was quite similar for both countries, with perhaps a little edge for the U.S. in 1911 and 1921. However the data for both countries are less reliable before 1931. As mentioned earlier, Canadian figures for this period are based on estimations. For the United States, figures concerned only death registration states before 1933 . 
Canadian Mortality in Perspective: A Comparison with the United States and other Developed Countries

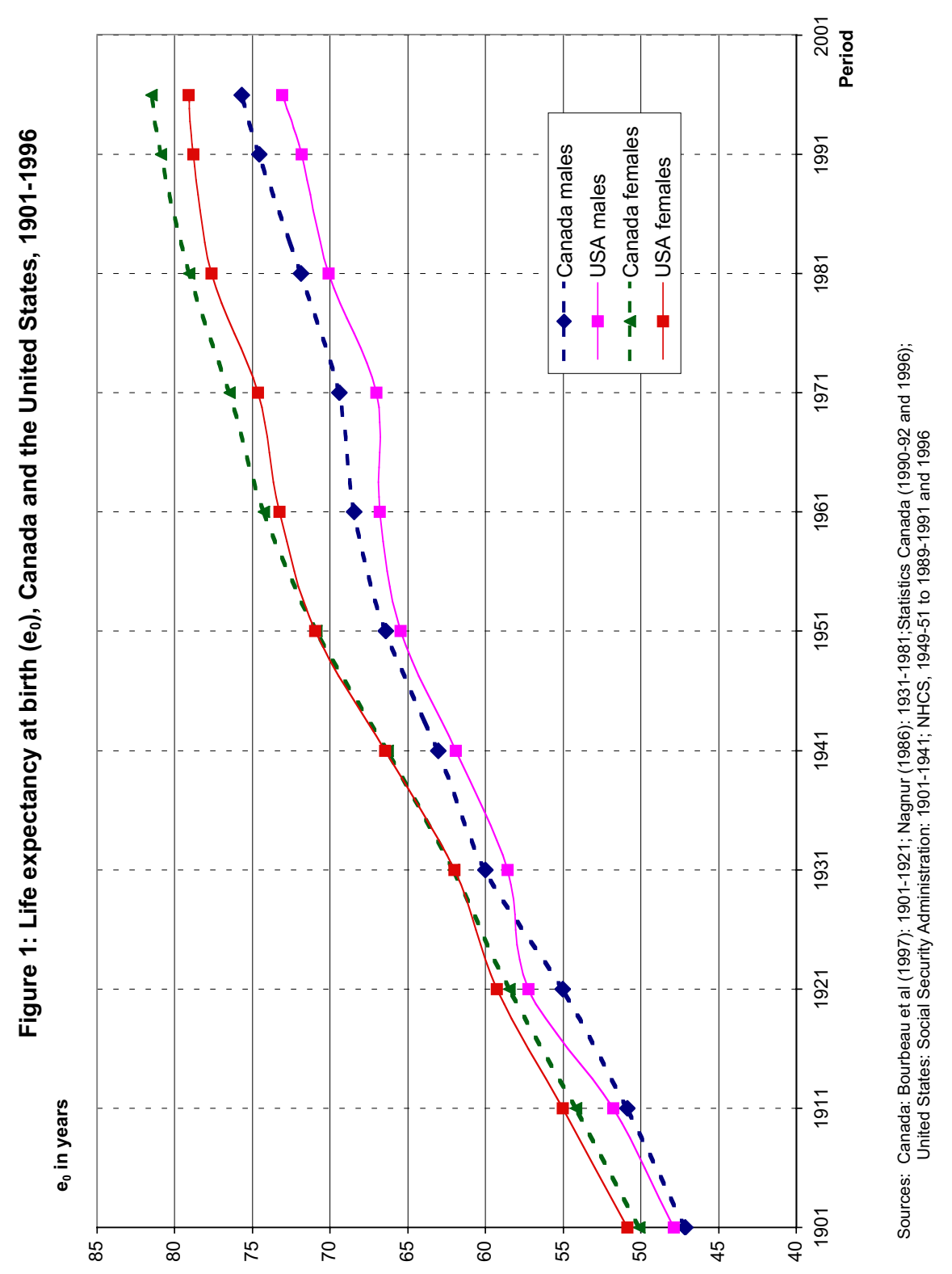


Robert Bourbeau

In 1931 Canada had a small advantage of about 1-year for men, but the gap increased over time to nearly 1.8 years in 1980 and 2.6 years in 1996. For women, life expectancy at birth was about the same for both countries from 1930 through 1960. Then Canada gained a one-year lead in 1970, and it increased to more than 2 years in 1996. So, Canadians have enjoyed a greater life expectancy at birth since 1931 for men, and since 1961 for women.

The difference between male and female mortality is higher in the US than in Canada since 1930, but the pattern is the same: there was an increase until 1980 and a decrease after, so females live about 6 years longer than males in both countries.

\section{Infant Mortality Rates, Canada and United States, 1901-1996}

Before the 1960s, mortality in the first year of life was lower in the United States. Therefore, infant mortality can not explain some of the Canadian advantages in life expectancy at birth before that period. After the $1960 \mathrm{~s}$, the trend reversed and Canadian infants had a lower mortality. The gap increased significantly by the early 1990s: $50 \%$ higher for boys and $42 \%$ for girls (Figure 2 ). It had been reduced to $30 \%$ and $36 \%$, respectively for boys and girls, by the mid 1990s.

Since 1970, infant mortality is one of the factors explaining the lower life expectancy at birth of Americans. We now take a closer look at the age-specific mortality rates in both countries.

\section{Age-Specific Mortality Rates by Sex, Canada and the United States, 1951 and 1995}

First, we examine the age-specific mortality rates in 1951 and in 1995, looking for differences between the countries. Then, we calculate the proportional reduction in age-specific mortality rates between 1951 and 1995 in order to show which age groups have benefited the most from the mortality reduction.

Comparing life expectancies at birth in 1951, we showed that there was no difference for females and about one year in Canada's favour for men. Figure 3a indicates that in 1951 female mortality rates in the USA were lower than Canadian mortality rates below age 25 and above age 75; the higher American mortality rates for females from age 25 to 74 explain why the overall level of mortality was the same for both countries. For men, American mortality rates were lower only below age 15 and above age 80; the excess American mortality from age 15 through age 79 more than offsets the lower mortality rates at both ends of the mortality curve (Figure $3 b$ ). 
Canadian Mortality in Perspective: A Comparison with the United States and other Developed Countries

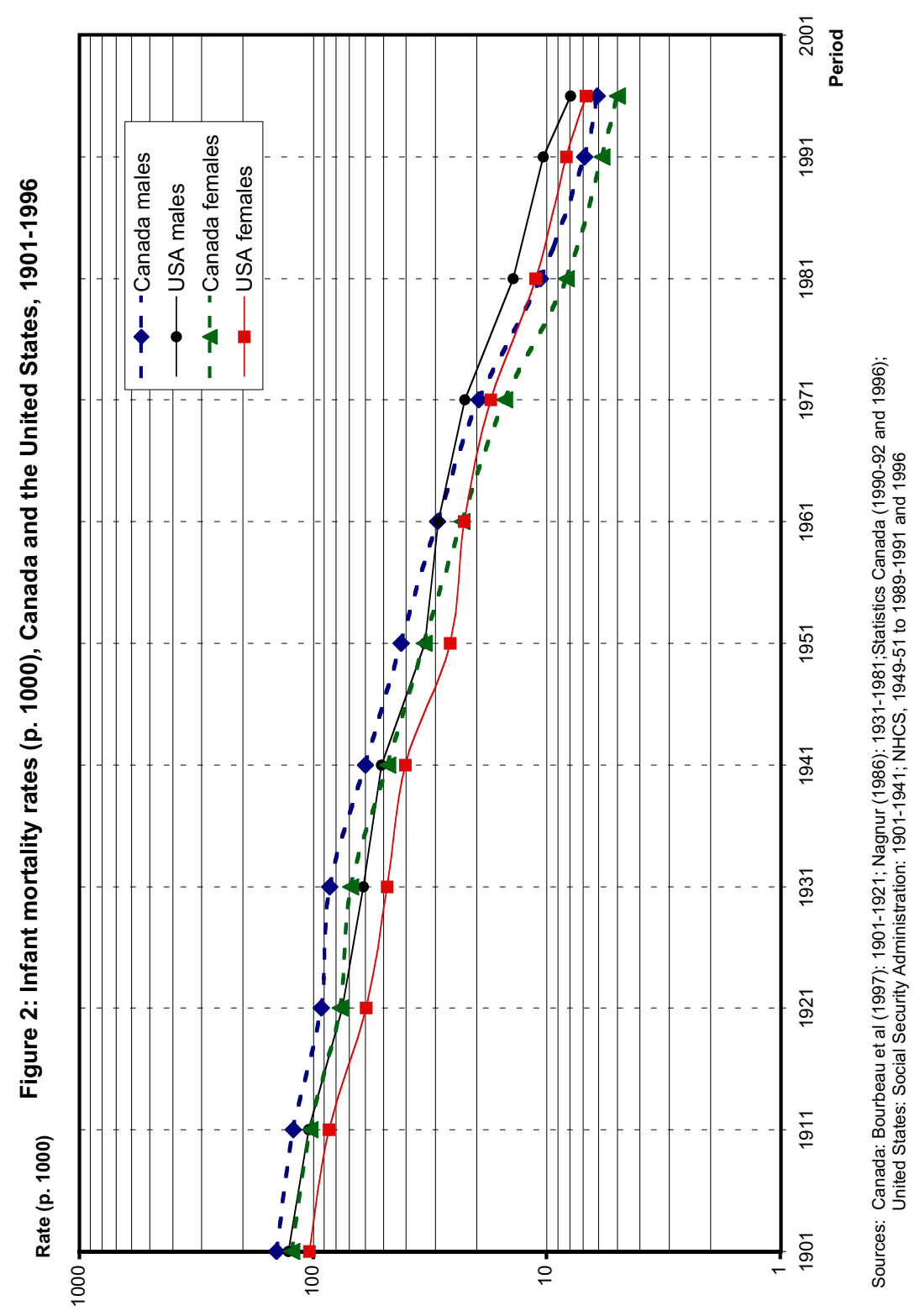


Robert Bourbeau

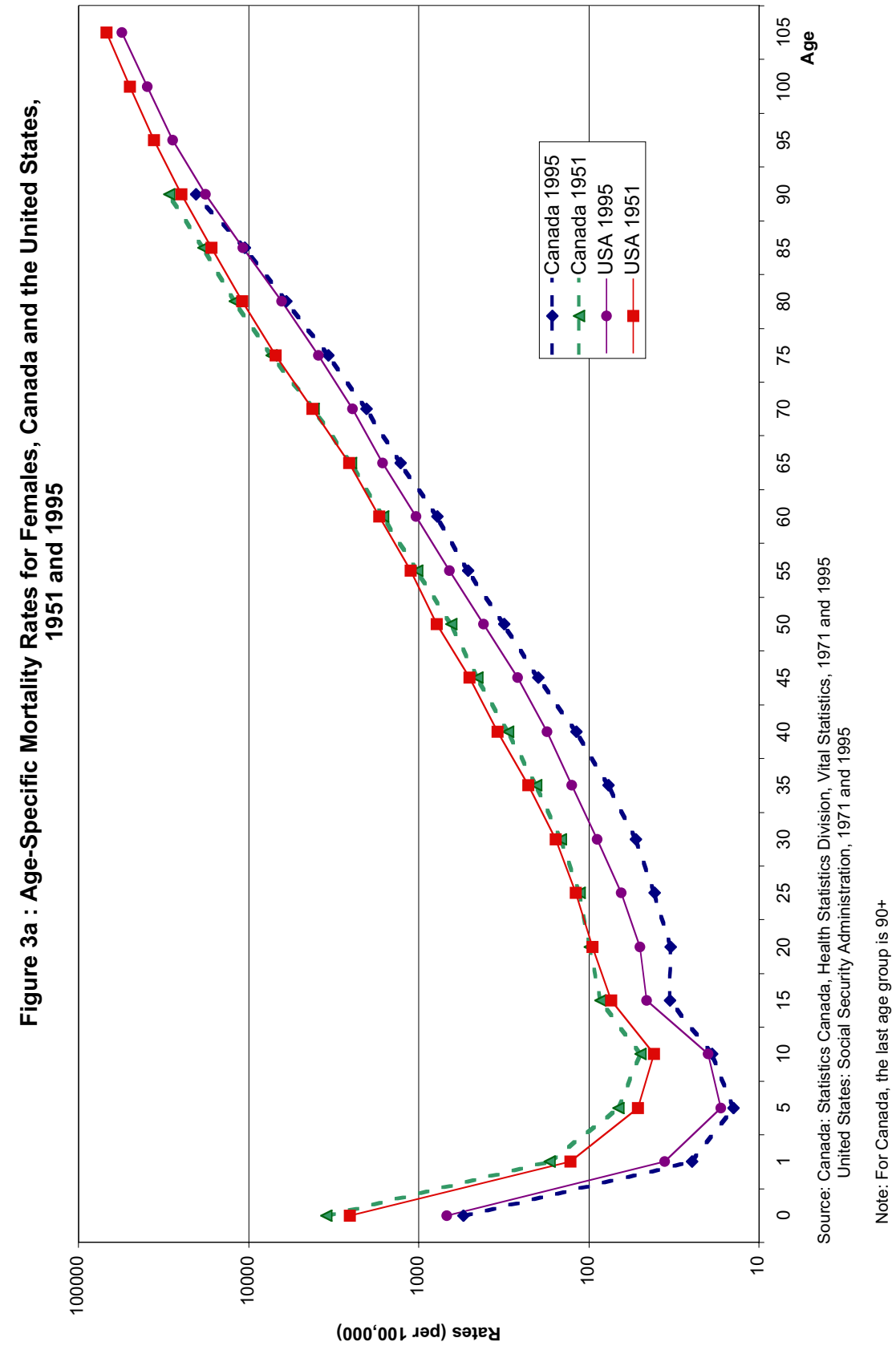

320 
Canadian Mortality in Perspective: A Comparison with the United States and other Developed Countries

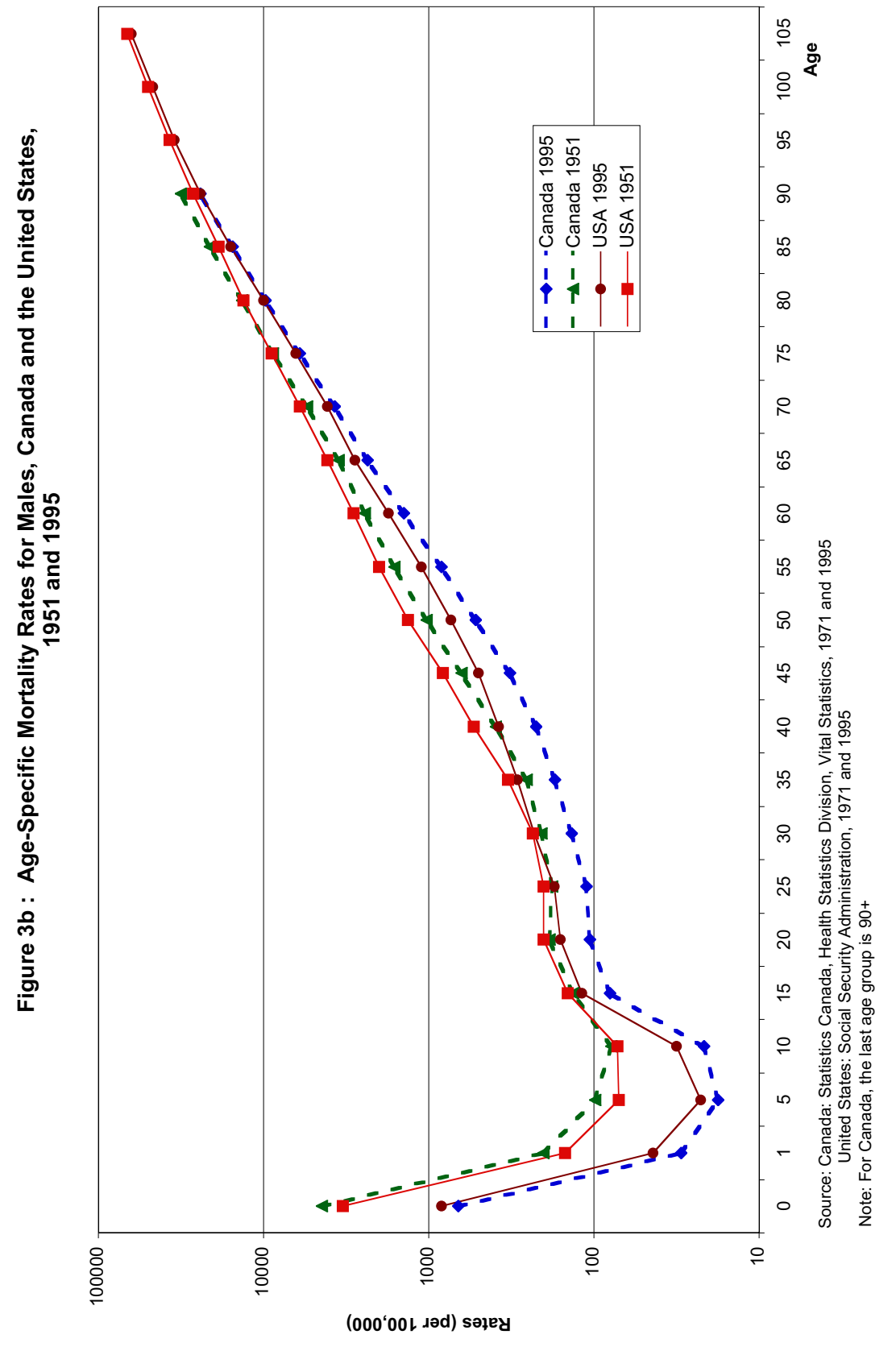


In 1995, the comparison between the two countries is straightforward For both sexes, age-specific mortality rates are lower in Canada for all age groups. Mortality rates above age 85 may be lower in the United States, but a lack of data for Canada does not allow a proper comparison. However, we know from other studies using special methods to estimate mortality rates for the oldest-old that American mortality is in fact similar to Canadian mortality (Bourbeau and Lebel, 2000). Calculating the proportional reductions in age-specific mortality rates during the period 1951-1995 reveals an interesting aspect of the comparison between the two countries. A similar study has been done for the period 1971-1989, with a focus on children and seniors (Ng, 1992).

Figures $4 \mathrm{a}$ and $4 \mathrm{~b}$ show that the proportional reductions between 1951 and 1995 were larger at all ages in Canada than in the United States, as expected. It also shows that the proportional reductions were greater among females than males, and also greater for children under age 15 than for any other age group; the mortality rate among infants decreased by more than $70 \%$ for both sexes. In contrast, the highest proportional reductions in mortality among the elderly were $54 \%$ in Canada and $44 \%$ in the US (for females aged 75 to 79 ) and $33 \%$ in Canada and $32 \%$ in the US (for males aged 65 to 69 ).

Another interesting point concerns the comparison between Canada and the US in proportional reductions. The difference was clearly higher from age 15 to 40 and clearly lower above age 65 , especially for women. The former result is an indication of the higher American mortality due to external causes, in particular for homicides. The latter result may be related to common factors in the two countries such as the same level of low mortality above age 80 that has prevailed since 1950, and similar health care programs for the elderly.

Thus, the proportional decline in mortality was consistently greater for all age groups in Canada than in the United States, but the difference was more important among children and young adults than among the elderly, especially for women. These trends in mortality reductions raised the issue of the availability of heath care in the two countries. It may reflect the fact that free universal Medicare is available to persons of all ages in Canada, while Medicare begins at age 65 in the United States, as already suggested by another study ( $\mathrm{Ng}$, 1992).

The background information given above allows a first comparison between Canada and the U.S. However, to determine the existence of a North American mortality profile, Canadian data has to be compared to the other developed countries as well as the US. The remaining part of this paper is devoted to such a comparison. 
Canadian Mortality in Perspective: A Comparison with the United States and other Developed Countries

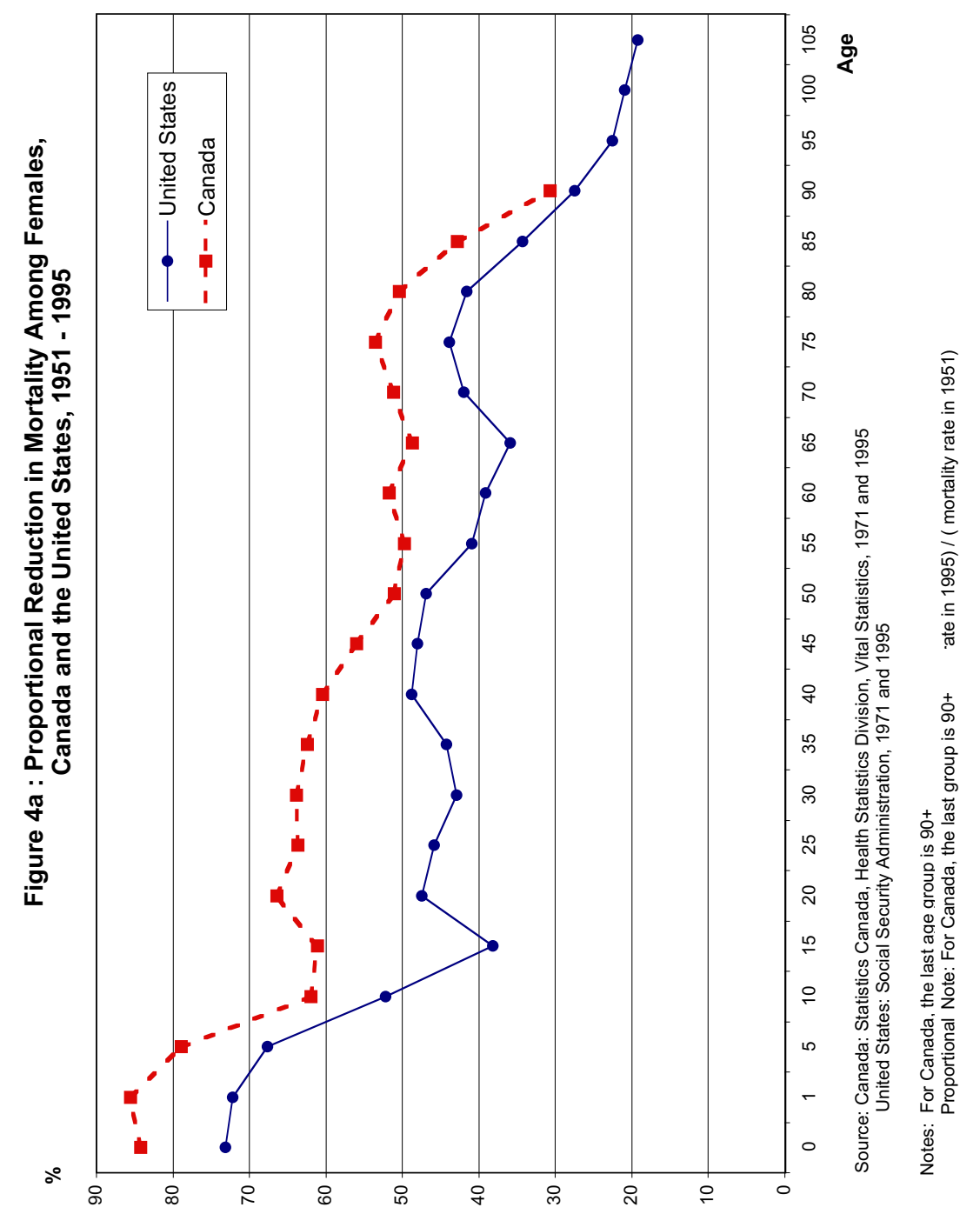


Robert Bourbeau

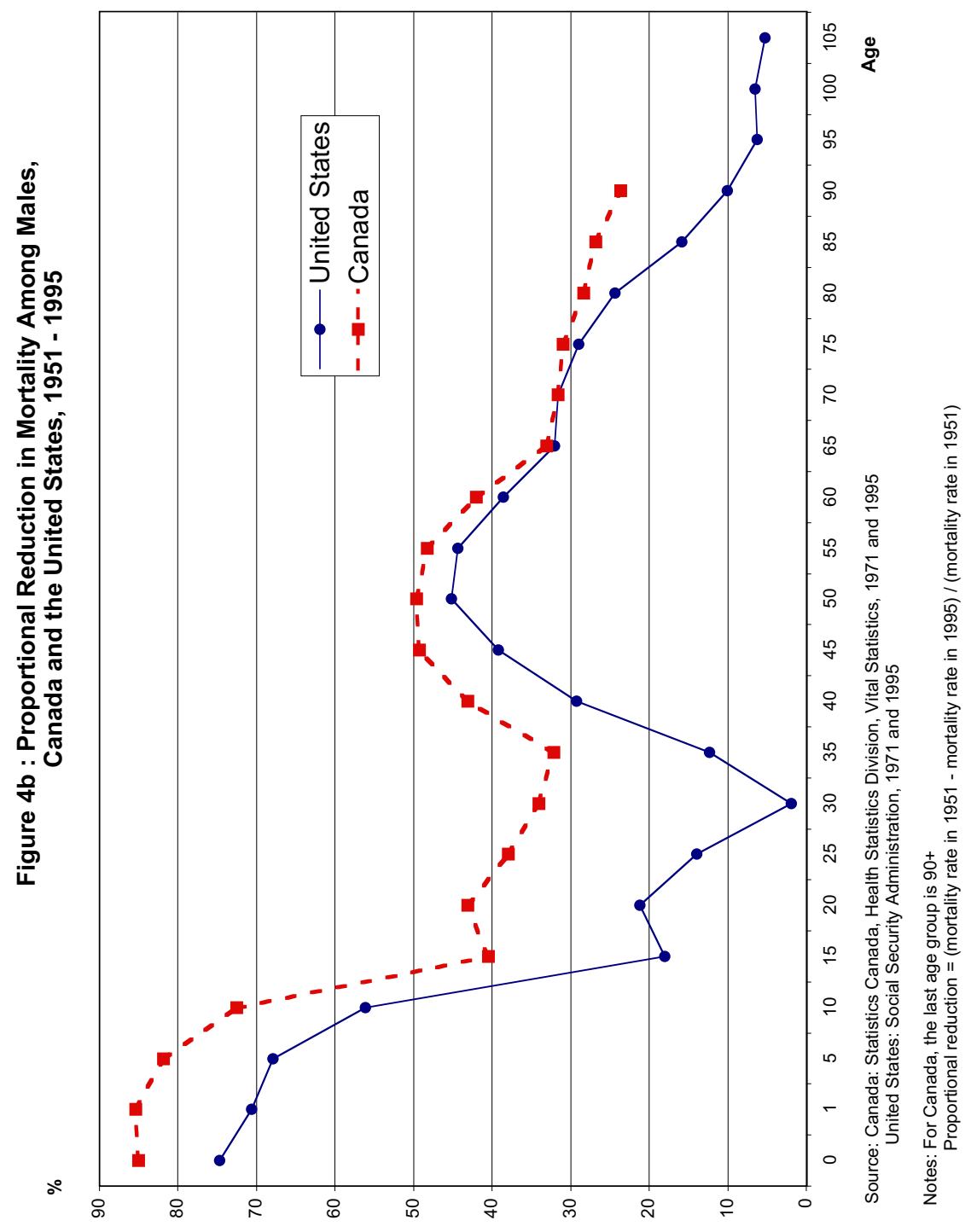


Canadian Mortality in Perspective:

A Comparison with the United States and other Developed Countries

\section{Data Sources}

Canadian mortality rates by age group were compared to those of 23 other developed countries during the period 1950-1995. Two sources of data were used: The WHO mortality database, and the UN Demographic Yearbook. Data for most of the countries during most years came from the WHO mortality data base (Table 1). The WHO data contain death counts by cause of death in 5-year age groups (up to $85+$ ), and corresponding population counts ${ }^{1}$, for most individual calendar years since the early 1950 s.

Figures from the UN Demographic Yearbook were used to fill in data that were missing in the WHO database, so that a complete series (of total mortality) is available for each country during the period 1950-1995. However the UN data are not available by cause of death, so all cause-specific analyses presented in this paper lack data for some countries in certain years.

The set of countries chosen for comparison with Canada includes most of the developed countries of Western Europe (20 countries), plus Japan, Australia, New Zealand and the United States. These countries have many similarities with Canada in terms of certain fundamental characteristics: high standards of living, competitive free-market economies, and a high degree of personal freedom.

This set of countries is not homogenous for all social or economic factors; there is always some diversity, like there is between Canadian provinces. This should not be a problem since the analysis focuses on the evolution of the relative position of Canada within the set of other countries, which is held constant to the extent possible.

The total population for the 24 countries considered in this study is about 827 million. The United States accounts for $32 \%$ of the total population, and Canada for about 3\%. This data set is almost the same used by Wilmoth (1998) in his comparative analysis of American mortality for the 1950-1991 period; in this study, figures are updated to 1995 for most of the countries.

\section{Methods}

\section{Ordinal Ranking}

A simple way to compare the countries is to rank them according to the levels of age-specific mortality rates. The evolution of this ranking is shown for a specific year, at 5-year intervals during the period 1950-1995. The ranking is based on observations for a single year, so there may be some random fluctuations between years. These rankings do not give an idea of the distribution of the rates 
Robert Bourbeau

Table 1

Sources of Data for 24 Countries, 1950-1995 and Population (in millions) as of 01.01.97

\begin{tabular}{|c|c|c|c|c|c|c|}
\hline \multirow{2}{*}{ Country } & \multicolumn{5}{|c|}{ Source of data } & \multirow{2}{*}{$\begin{array}{l}\text { Population } \\
\text { 01.01.1997 } \\
\text { (in millions) }\end{array}$} \\
\hline & UN* & $\begin{array}{l}\text { WHO } \\
\text { ICD7 }\end{array}$ & $\begin{array}{l}\text { WHO } \\
\text { ICD8 }\end{array}$ & $\begin{array}{l}\text { WHO } \\
\text { ICD9 }\end{array}$ & $\begin{array}{c}\text { WHO } \\
\text { ICD10 }\end{array}$ & \\
\hline Australia & & $50-67$ & $68-78$ & $79-95$ & & 18.4 \\
\hline Austria & $50-54$ & $55-68$ & $69-79$ & $80-95$ & & 8.0 \\
\hline Belgium & $50-53$ & $54-67$ & $68-78$ & $79-94$ & & 10.1 \\
\hline Canada & & $50-68$ & $69-78$ & $79-95$ & & 29.8 \\
\hline Denmark & 50 & $52-68 * *$ & $69-93$ & & $94-95$ & 5.2 \\
\hline England \& Wales & & $50-67$ & $68-78$ & $79-95$ & & 51.9 \\
\hline Finland & $50-51$ & $52-68$ & $69-86$ & $87-95$ & & 5.1 \\
\hline France & & $50-67$ & $68-78$ & $79-95$ & & 58.5 \\
\hline Germany & $50-51$ & $52-67$ & $68-78$ & $79-95$ & & 82.0 \\
\hline Greece & $51-55$ & $56-67$ & $68-78$ & $79-95$ & & 10.5 \\
\hline Iceland & & $51-70$ & $71-80$ & $81-95$ & & 0.3 \\
\hline Ireland & & $50-67$ & $68-78$ & $79-95$ & & 3.6 \\
\hline Italy & 50 & $51-67$ & $68-78$ & $79-95$ & & 57.5 \\
\hline Japan & & $50-67$ & $68-78$ & $79-94$ & 95 & 125.7 \\
\hline Luxembourg & $56-64$ & $55-62,65-70$ & $71-78$ & $79-95$ & & 0.4 \\
\hline Netherlands & & $50-68$ & $69-78$ & $79-95$ & & 15.6 \\
\hline New Zealand & & $50-67$ & $68-78$ & $79-95$ & & 3.8 \\
\hline Norway & 50 & $51-68$ & $69-85$ & $86-95$ & & 4.4 \\
\hline Portugal & $50-54$ & $55-70$ & $71-79$ & $80-95$ & & 9.9 \\
\hline Scotland & 50 & $50-67$ & $68-78$ & $79-95$ & & 5.1 \\
\hline Spain & & $51-67$ & $68-79$ & $80-95$ & & 39.3 \\
\hline Sweden & & $51-68$ & $69-86$ & $87-95$ & & 8.7 \\
\hline Switzerland & 50 & $51-68$ & $69-94$ & & & 7.0 \\
\hline United States & & $50-67$ & $68-78$ & $79-95$ & & 266.5 \\
\hline
\end{tabular}

Notes: UN: United Nations; WHO: World Health Organisation; ICD: International Classification of Diseases In addition to Canada and the United States, italicized countries are outside Western Europe.

* UN data is not broken down by cause of death, so these data are only used in Table 4.

** WHO data for Denmark in 1951 are in an age format which cannot be converted into the categories used in this analysis.

Source: Population: INED (1999). 
Canadian Mortality in Perspective:

A Comparison with the United States and other Developed Countries

among the countries. If the standard error is small, we may observe large

changes in the ranking due to very small changes in the rates.

\section{Rate Ratios: Total Mortality}

A second indicator of relative status is the ratio of mortality rates by age and sex in Canada to mortality rates by age and sex for an aggregate of the other developed countries. These mortality rate ratios are calculated for ten-year periods, except for the last period which includes six years, 1990-1995. Rate ratios $^{2}$ lead to a better comparison between Canada and the other countries than the ordinal ranking, because they allow us to see the relative magnitude of differences.

We performed the calculations removing the United States data from the aggregate for the following reasons. We are looking for a distinctive mortality pattern for Canada, when compared to other developed countries. Since our hypothesis is that Canada presents similar characteristics with the USA, we have to remove it from the aggregate. This is very important because the U.S. constitutes a large portion of the aggregate in terms of population and death counts (nearly 33\%) and because the U.S. experienced a large increase in its mortality rate ratios below age 65 . It is interesting to see how Canadian mortality performs when the U.S. is not included in the comparison.

The same rate ratios have been calculated for the United States (Wilmoth, 1998). Canadian data were included in the aggregate of other developed countries when calculating the rate ratios for the United States, however that should not be a problem since Canada accounted for a small proportion $(3.6 \%)$ of the aggregate population.

\section{Rate Ratios: Cause-specific Mortality}

Rate ratios can also be calculated for each specific group of causes of death, allowing a better understanding of the evolution of the overall rate ratios. Equation 1 shows the relationship between the rate ratios for total and causespecific mortality for two populations:

$$
R=\frac{M^{C D}}{M^{A g}}=\sum_{i}\left[p^{A g}(i) \cdot \frac{M^{C D}(i)}{M^{A g}(i)}\right]=\sum_{i}\left[p^{A g}(i) \cdot R(i)\right]
$$

where, for some combination of age, sex and year, $M^{C D}$ and $M^{A g}$ are total death rates for Canada and the aggregate of other developed countries, respectively; 
$M^{C D}(i)$ and $M^{A g}(i)$ are mortality rates for cause $i ; R$ and $R(i)$ are the rate ratios for total and cause specific mortality, respectively; and $\mathrm{p}^{\mathrm{Ag}}(i)$ is the proportion of deaths in the aggregate population due to cause $i^{3}$.

Thus, the rate ratios for total mortality equals the weighted average of the rate ratios for cause-specific mortality, where the weights are the proportion of deaths due to each cause in the aggregate population (Wilmoth, 1998). This relation is used to help explain the changes in overall rate ratios (for total mortality).

\section{Categories of Cause of Death}

Table 2 shows the breakdown of deaths by cause used in this paper. There are eleven categories of deaths: infectious and parasitic diseases, malignant neoplasms, cerebrovascular diseases, diseases of the heart, diseases of the respiratory system, diseases of the digestive system, motor-vehicle accidents, other accidents, suicide, homicide and a large residual category grouping all other causes. This set of categories is the same as the one analysed by Wilmoth (1998), except for a breakdown of the diseases of the circulatory system in two groups: diseases of the heart and cerebrovascular diseases.

The table shows the cause groupings and gives the A- or B-list codes of each category for the relevant revisions $\left(7^{\text {th }}, 8^{\text {th }}\right.$, and $\left.9^{\text {th }}\right)$ of the International Classification of Diseases (ICD). Some countries already use the $10^{\text {th }}$ Revision of the ICD: Denmark, and Japan. For this revision, the three character categories were retained for cause groupings.

\section{Decomposition Method}

For the interpretation of the evolution of mortality rate ratios over time, it is necessary to quantify the importance of each factor identified in Equation 1: cause specific mortality rate ratio and proportion of deaths due to each cause in the aggregate population. We have used the decomposition method suggested by Das Gupta (1993, p.6-7), and already used by Wilmoth (1998) for the United States.

Suppose that we are comparing mortality rate ratios for two populations at two moments in time: for example, Canada and the aggregate of other developed countries considered here, during the 1950s and the mid 1990s. Let $R_{l}$ and $R_{2}$ be the rate ratios (for some age-sex group) in the earlier and the later time periods, respectively. Then, by Equation 1 given above, the change in rate ratios can be written as a function of cause-specific rate ratios and proportions of deaths by cause for each period: 
Canadian Mortality in Perspective: A Comparison with the United States and other Developed Countries

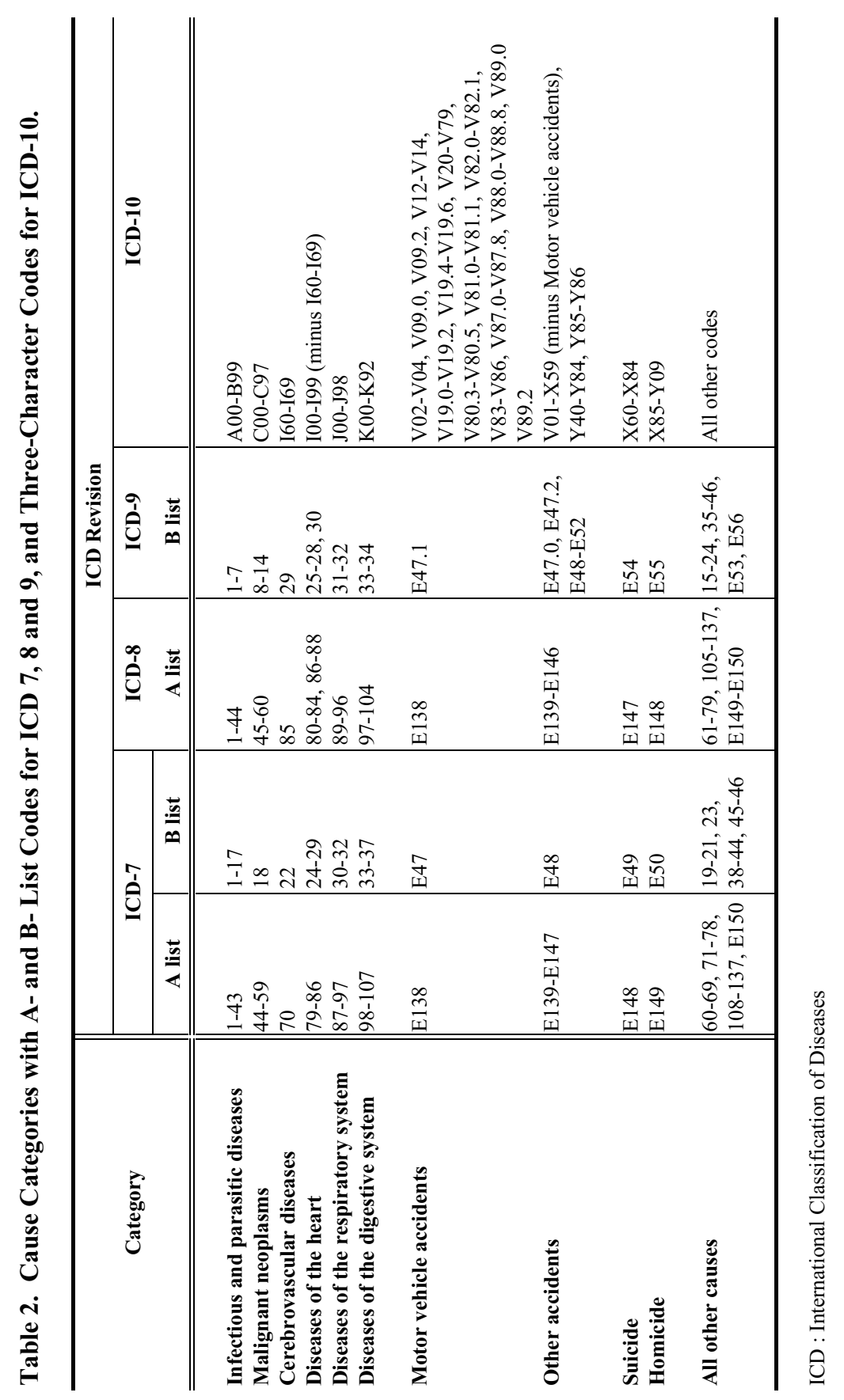


Robert Bourbeau

$$
\begin{aligned}
& \Delta R=R_{2}-R_{1} \\
& \Delta R=\sum_{i}^{A g}\left(p_{2}(i) \cdot R_{2}(i)\right]-\sum_{i}\left[p_{1}^{A g}(i) \cdot R_{I}(i)\right] \\
& \Delta R=\sum_{i}^{i}\left[p_{2}^{A g}(i) \cdot R_{2}(i)-p_{1}^{A g}(i) \cdot R_{I}(i)\right]
\end{aligned}
$$

Thus, the $i^{\text {th }}$ element of this sum reflects the contribution of cause $i$ to the change in the relative risk of total mortality. This component, however, may reflect changes in either the cause-specific rate ratios or in the proportion of all deaths due to that cause (for this particular age-sex group).

To complete the decomposition, the $i^{\text {th }}$ element of each sum is broken into two parts. Dropping extraneous subscripts, it is simple to show that

$$
p_{2} R_{2}-p_{1} R_{1}=\bar{p} \cdot \Delta R+\bar{R} \cdot \Delta p
$$

where

$$
\bar{p}=\frac{1}{2}\left(p_{1}+p_{2}\right), \bar{R}=\frac{1}{2}\left(R_{1}+R_{2}\right), \Delta p=p_{2}-p_{1}, \Delta R=R_{2}-R_{1}
$$

Thus, by holding the proportion of deaths for cause $i$ constant (at its average value $\bar{p}$ ), the first element on the right side of this equation measures the change in the total rate ratio attributable to the change in the rate ratio due to cause $i$ during the time period in question. Likewise, by holding constant the cause-specific rate ratio ( $\bar{R}$ ), the second element represents the change in total rate ratio attributable to changes in the proportion of deaths due to cause $i$. Thus, the full decomposition can be written as follows (Equation 2):

$$
\Delta R=\sum_{i}\left[\bar{p}^{A g}(i) \cdot \Delta R(i)+\bar{R}(i) \cdot \Delta p^{A g}(i)\right]
$$

This equation has been applied to changes in mortality rate ratios from the 1950 s to the mid 1990 s. 
Canadian Mortality in Perspective:

A Comparison with the United States and other Developed Countries

\section{Results}

In this section, the changes in the relative ranking of Canadian mortality are documented through an examination of both total and cause-specific mortality rates. Comparisons to the United States are also presented.

\section{Evolution of the Relative Ranking for Canada}

Total mortality: ordinal ranking

Table 3a shows the evolution of the ordinal rankings of Canadian age-specific mortality rates at 5-year intervals from 1950 to 1995 . In this analysis, seven broad age groups are considered: infants (age 0), children (1-14), adolescents and young adults (15-24), adults (25-39), middle-age adults (40-64), young elderly (65-79), and oldest-old (80+). These are almost the same groups used in Wilmoth's paper (1998), except for the fact that we have divided the 15-39 group into two subgroups.

In 1950, Canada had a good ranking (but not outstanding) for all age groups, except for infants and for children and adolescents (1-14), where Canada ranked $10^{\text {th }}$ and $12^{\text {th }}$ among 20 countries. Canada was already among the best countries for ages 65 and over (fourth at 65-79 and second behind the U.S. for the $80+)^{4}$.

By 1955, the Canadian mortality ranking had deteriorated significantly in all age groups, probably because many European countries experienced health improvements after World War II. Canada was no long among the ten best countries for mortality under 25 , but was still in that privileged group over age 25. The Canada's ranking remained quite stable from 1955 to 1970 , except for a deterioration among young adults and an improvement among 80+.

The deterioration in ranking continued to 1975 for the age groups 1-14 to 40-64. In fact, Canada experienced its worst ranking in the 1970s. Over age 65, the ranking of Canada had not deteriorated but instead had improved, so that Canadian mortality ranked $6^{\text {th }}$ for the $65-79$ age group and $3^{\text {rd }}$ for the oldest-old.

From 1980 on, there have been large improvements in all age groups, but in particular, for infant mortality (except in 1995) and for persons 40-64 years old.

\section{Comparisons with the United States}

When compared to the United States, Canada had a much better ranking in 1995 for all age groups (Table 3b). But this was not always the case. U.S. rankings had been better for infant mortality from 1950 through 1960, for children and 
Robert Bourbeau

Table 3a

Ordinal Ranking of Canadian Age-Specific Death Rates for Both Sexes, 1950-1995

\begin{tabular}{|c|c|c|c|c|c|c|c|c|}
\hline \multirow[b]{2}{*}{ Year } & \multicolumn{7}{|c|}{ Age Group } & \multirow{2}{*}{$\begin{array}{l}\text { Number of } \\
\text { Countries }\end{array}$} \\
\hline & $\mathbf{0}$ & $1-14$ & $15-24$ & 25-39 & $40-64$ & $65-79$ & $\mathbf{8 0}+$ & \\
\hline 1950 & 10 & 12 & 6 & 6 & 9 & 4 & 2 & 20 \\
\hline 1955 & 13 & 15 & 14 & 10 & 9 & 7 & 8 & 23 \\
\hline 1960 & 14 & 17 & 18 & 10 & 8 & 8 & 7 & 24 \\
\hline 1965 & 14 & 17 & 21 & 11 & 9 & 8 & 3 & 24 \\
\hline 1970 & 13 & 16 & 18 & 11 & 9 & 6 & 3 & 24 \\
\hline 1975 & 12 & 21 & 22 & 18 & 11 & 6 & 3 & 24 \\
\hline 1980 & 11 & 19 & 19 & 15 & 12 & 6 & 2 & 24 \\
\hline 1985 & 6 & 11 & 17 & 11 & 8 & 5 & 1 & 24 \\
\hline 1990 & 5 & 16 & 12 & 12 & 8 & 6 & 3 & 24 \\
\hline 1995 & 14 & 11 & 12 & 10 & 6 & 6 & 2 & 22 \\
\hline
\end{tabular}

Table 3b

rrdinal Ranking of United States Age-Specific Death Rates for Both Sexes, 1950-199

\begin{tabular}{|c|c|c|c|c|c|c|c|c|}
\hline \multirow[b]{2}{*}{ Year } & \multicolumn{7}{|c|}{ Age Group } & \multirow{2}{*}{$\begin{array}{l}\text { Number of } \\
\text { Countries }\end{array}$} \\
\hline & $\mathbf{0}$ & 1-14 & $15-24$ & $25-39$ & $40-64$ & $65-79$ & $\mathbf{8 0 +}$ & \\
\hline 1950 & 7 & 3 & 7 & 9 & 17 & 7 & 1 & 20 \\
\hline 1955 & 10 & 5 & 16 & 16 & 21 & 8 & 2 & 23 \\
\hline 1960 & 12 & 11 & 20 & 21 & 20 & 10 & 1 & 24 \\
\hline 1965 & 17 & 11 & 23 & 22 & 21 & 11 & 2 & 24 \\
\hline 1970 & 17 & 10 & 23 & 24 & 21 & 12 & 1 & 24 \\
\hline 1975 & 15 & 15 & 21 & 23 & 20 & 9 & 2 & 24 \\
\hline 1980 & 18 & 17 & 24 & 24 & 22 & 11 & 3 & 24 \\
\hline 1985 & 20 & 22 & 21 & 23 & 21 & 8 & 3 & 24 \\
\hline 1990 & 23 & 22 & 22 & 24 & 20 & 11 & 5 & 24 \\
\hline 1995 & 21 & 20 & 20 & 21 & 18 & 15 & 6 & 22 \\
\hline
\end{tabular}




\section{Canadian Mortality in Perspective: \\ A Comparison with the United States and other Developed Countries}

adolescents (1-14 years old) from 1950 through 1985, and for the $80+$ from 1950 to 1975 . Otherwise, Canada had a better ranking (with one exception, in 1975 for the 15-24 years old).

Another important feature of the Canadian mortality pattern is the fact that its ranking among other developed countries improves as age increases, so that the best ordinal rankings for Canada are above age 40, in particular above age 80 where Canada is second to Japan.

\section{Total Mortality: Mortality Rate Ratios}

Table 4 a compares the mortality rate ratios by age and sex in Canada to comparable values for an aggregate of 22 other developed countries (the United States was omitted from the aggregate for reasons stated above).

These rate ratios give almost the same picture as table $3 \mathrm{a}$ in terms of the evolution of relative mortality although the rate ratios allow quantifying the gap between Canadian mortality and the aggregate. Table $4 \mathrm{a}$ also allows a comparison by sex, but there are no real differences by sex in the evolution of mortality rate ratios.

In the fifties, Canada's mortality rate ratios were very low. Its rate ratios were below the average (100) for all age groups (mainly from ages 1 to 40). Then there was an increase of Canada's rate ratios for all age groups, except for males aged 40-64 and for females above age 80 . The increase was more noticeable among the 1-39 age group, probably due to the excess mortality levels related to external causes in Canada (motor vehicle accidents, suicides).

Canada's increase in rate ratios relative to other developed countries was not as significant as in the USA (Wilmoth, 1998). Table 4b shows that in the 1950s, the rate ratios for the US were quite good (below the average for most of the age groups or slightly above for some, such as at ages 40-64 for females, and 15-64 for males). Although the US ranked first (in ordinal ranking) for the $80+$, its rate ratio was not exceptionally low (85).

By the 1990s in the United States, ratios compared to other developed countries had increased substantially in almost every age group: typically ranging from 125 to 166 (mainly below age 40). At older ages, the relative rankings were better, especially for the $80+$, where the rate ratio remained below the average (about 95). This large increase in the US rate ratios at most ages leads to an unusual pattern by age, that corresponds to the so-called North American mortality pattern: relatively higher mortality below age 65 , and relatively lower mortality above age 65 , especially above age 80 . 
Table 4a

Mortality Rate Ratios by Age Group and Sex (x 100), 1950-1959 to 1990-1995

Canada versus Aggregate of Other Developed Countries

\begin{tabular}{cccccccc}
\hline & \multicolumn{7}{c}{ Age group } \\
\cline { 2 - 8 } Period & $\mathbf{0}$ & $\mathbf{1 - 1 4}$ & $\mathbf{1 5 - 2 4}$ & $\mathbf{2 5 - 3 9}$ & $\mathbf{4 0 - 6 4}$ & $\mathbf{6 5 - 7 9}$ & $\mathbf{8 0 +}$ \\
\hline \hline & Females & & & & & & \\
$\mathbf{1 9 5 0 - 1 9 5 9}$ & 81 & 59 & 64 & 69 & 92 & 88 & 91 \\
$\mathbf{1 9 6 0 - 1 9 6 9}$ & 94 & 86 & 95 & 85 & 90 & 87 & 88 \\
$\mathbf{1 9 7 0 - 1 9 7 9}$ & 95 & 101 & 117 & 101 & 101 & 85 & 82 \\
$\mathbf{1 9 8 0 - 1 9 8 9}$ & 94 & 105 & 116 & 99 & 108 & 90 & 86 \\
$\mathbf{1 9 9 0 - 1 9 9 5}$ & 104 & 100 & 112 & 98 & 102 & 99 & 89 \\
& & & & & & & \\
& Males & & & & & & \\
$\mathbf{1 9 5 0 - 1 9 5 9}$ & 85 & 70 & 93 & 83 & 93 & 87 & 87 \\
$\mathbf{1 9 6 0 - 1 9 6 9}$ & 95 & 92 & 119 & 96 & 91 & 91 & 86 \\
$\mathbf{1 9 7 0 - 1 9 7 9}$ & 94 & 104 & 142 & 111 & 105 & 91 & 91 \\
$\mathbf{1 9 8 0 - 1 9 8 9}$ & 94 & 106 & 130 & 108 & 100 & 93 & 93 \\
$\mathbf{1 9 9 0 - 1 9 9 5}$ & 101 & 99 & 111 & 100 & 87 & 97 & 92 \\
\hline
\end{tabular}

Note: Without US in aggregate

Table 4b

Mortality Rate Ratios by Age Group and Sex (x 100), 1950-1959 to 1990-1995 United States versus Aggregate of Other Developed Countries

\begin{tabular}{cccccccc}
\hline & \multicolumn{7}{c}{ Age group } \\
\cline { 2 - 8 } Period & $\mathbf{0}$ & $\mathbf{1 - 1 4}$ & $\mathbf{1 5 - 2 4}$ & $\mathbf{2 5 - 3 9}$ & $\mathbf{4 0 - 6 4}$ & $\mathbf{6 5 - 7 9}$ & $\mathbf{8 0 +}$ \\
\hline \hline & Females & & & & & & \\
$\mathbf{1 9 5 0 - 1 9 5 9}$ & 69 & 48 & 70 & 82 & 106 & 87 & 85 \\
$\mathbf{1 9 6 0 - 1 9 6 9}$ & 92 & 81 & 113 & 119 & 113 & 92 & 88 \\
$\mathbf{1 9 7 0 - 1 9 7 9}$ & 107 & 97 & 131 & 127 & 125 & 91 & 81 \\
$\mathbf{1 9 8 0 - 1 9 8 9}$ & 124 & 116 & 144 & 130 & 134 & 100 & 89 \\
$\mathbf{1 9 9 0 - 1 9 9 5}$ & 140 & 125 & 153 & 151 & 134 & 116 & 95 \\
& & & & & & & \\
& Males & & & & & & \\
$\mathbf{1 9 5 0 - 1 9 5 9}$ & 74 & 55 & 104 & 101 & 118 & 93 & 84 \\
$\mathbf{1 9 6 0 - 1 9 6 9}$ & 95 & 83 & 132 & 125 & 117 & 100 & 86 \\
$\mathbf{1 9 7 0 - 1 9 7 9}$ & 106 & 100 & 146 & 143 & 127 & 98 & 86 \\
$\mathbf{1 9 8 0 - 1 9 8 9}$ & 121 & 117 & 149 & 155 & 121 & 97 & 93 \\
$\mathbf{1 9 9 0 - 1 9 9 5}$ & 139 & 129 & 161 & 166 & 115 & 105 & 95 \\
\hline
\end{tabular}


Canadian Mortality in Perspective:

A Comparison with the United States and other Developed Countries

This pattern was not found for Canada. By 1990-1995, compared to other developed countries, there was only a slightly higher mortality rate ratio among the 15-24 age group, due to relatively higher death rates for suicide. The Canadian mortality pattern is less unusual than the American pattern. Canadian mortality rate ratios are more consistent across the age groups. They fluctuate from 89 to 112 for females and from 87 to 111 for males. While the mortality rate ratios for the oldest-old are low, they are not as different from the other age groups as for the US.

But there is still a relatively lower level of mortality for the oldest-old $(80+)$ in Canada, and it is only this which constitutes the North American mortality pattern. This is the common feature for both countries and it has persisted during the whole period.

Two results need a closer examination and explanation:

- What can explain the increase in mortality rate ratios in Canada compared to other developed countries for all age groups, except the $80+$ for females and the 40-64 for males, during the 1950-1995 period? To answer this question, we have to introduce the cause-specific death rates, the proportion of deaths for each category of causes of death, and a decomposition method to show the respective contribution of these two components.

- What can explain the lower mortality in Canada among the 80 + ? To answer this question, we will raise some hypotheses.

\section{The Increase in Rate Ratios for Total Mortality: Possible Interpretations}

\section{Cause-specific Mortality}

For explanation of the evolution of rate ratios for total mortality in Canada, we can look at the causes of deaths, and calculate cause-specific rate ratios for each age group and sex.

Changes in the relative position of Canada in terms of total mortality can be decomposed as a function of changes in cause-specific mortality. In the formula shown above (Equation 1), the contribution of each cause category to the mortality rate ratio for all causes is a function of two components: the proportion of deaths due to that cause in the aggregate population and the death rate ratio for that individual cause. Likewise, changes in the death rate ratio for all causes are a function of changes in these two components (Wilmoth, 1998). This relation is used to help explain the changes in rate ratios for total mortality for 
Robert Bourbeau

Canada during the 1950-1995 period.

Changes are defined here as the difference between the mortality rate ratios in the 1950s (1950-1959) and the corresponding rate ratio in the 1990s (19901995). For example (see table 4a), the rate ratio for infant females in Canada was equal to $R_{1}=81$ in the $1950 \mathrm{~s}$ and to $R_{2}=104$ in the mid $1990 \mathrm{~s}$ : so the difference between the rate ratios $\left(R_{2}-R_{1}\right)=23$. A positive difference means an increase in rate ratios * 100 (which is bad). As well, the rate ratio for Canadian men in age group 40-64 was equal to $R_{1}=93$ in the 1950 s and to $R_{2}=87$ in the mid 1990s: so the difference between the ratios $\left(R_{2}-R_{1}\right)=-6$. A negative difference means a decrease in rate ratios $* 100$ (which is good).

These changes in the rate ratios for total mortality may be due either to shifts in the distribution of deaths by cause or to trends in the rate ratios for causespecific mortality (as suggested by Equation 1).

Thus, there are at least two possible interpretations of the changes in the relative position of Canada in terms of total mortality.

1. The first interpretation is that the changes in rate ratios for total mortality were due to similar changes in cause-specific mortality. However, figures 5.1 to 5.12 show that changes in cause-specific mortality were diverse, both in terms of levels and trends.

2. The alternate interpretation is that the distribution of deaths by cause has shifted to those causes where the relative position of Canada is more or less favourable. For example, during the 1950-1995 period, the disease profile shifted to include more external causes, like suicides, where Canada had a less favourable experience. This change in the distribution of deaths by cause may have contributed to observed trends in the rate ratios for total mortality.

In fact, both factors are responsible for the changes in the rate ratios for total mortality; it is necessary to quantify the relative importance of each factor. The classic answer to this problem is to use a decomposition method (Equation 2). Before getting into the results of the decomposition, we explore the changes in these two individual components from the 1950s to the mid 1990s.

\section{Changes in Proportion of Deaths by Cause from 1950 to 1995}

Table 5 presents changes in the proportions of deaths by cause from the 1950s to the mid 1990s in the aggregate population (for both sexes combined). According to the epidemiological transition (Omran, 1971), we are expecting a decrease in 
Canadian Mortality in Perspective: A Comparison with the United States and other Developed Countries

Table 5

Percentage Distribution of Deaths by Cause and Age Group, Aggregate of 22 Developed Countries for both Sexes, 1950-1959, 1970-1979 and 1990-1995 (excluding Canada and the United States)

Aggregate without the USA

\begin{tabular}{|c|c|c|c|c|c|c|c|}
\hline \multirow{2}{*}{$\begin{array}{c}1950-1959 \\
\text { Causes of death }\end{array}$} & \multicolumn{7}{|c|}{ Age group } \\
\hline & $\mathbf{0}$ & $1-14$ & $15-24$ & 25-39 & $40-64$ & $65-79$ & $80+$ \\
\hline Infectious & 4 & 22 & 21 & 23 & 7 & 2 & 1 \\
\hline Neoplasms & 0 & 4 & 5 & 11 & 24 & 16 & 8 \\
\hline Cereberovascular & 0 & 0 & 1 & 3 & 12 & 19 & 16 \\
\hline Diseases of heart & 0 & 3 & 7 & 11 & 22 & 30 & 32 \\
\hline Respiratory & 17 & 15 & 4 & 4 & 6 & 8 & 10 \\
\hline Digestive & 10 & 15 & 5 & 7 & 8 & 5 & 3 \\
\hline MotorVehicle & 0 & 4 & 11 & 6 & 2 & 0 & 0 \\
\hline OtherAccidents & 2 & 13 & 14 & 9 & 3 & 1 & 2 \\
\hline Suicide & 0 & 0 & 12 & 7 & 2 & 1 & 0 \\
\hline Homicide & 0 & 1 & 1 & 1 & 0 & 0 & 0 \\
\hline Other & 67 & 22 & 18 & 19 & 13 & 16 & 28 \\
\hline All Causes & 100 & 100 & 100 & 100 & 100 & 100 & 100 \\
\hline 1970-1979 & \multicolumn{7}{|c|}{ Age group } \\
\hline Causes of death & $\mathbf{0}$ & $1-14$ & $15-24$ & 25-39 & $40-64$ & $65-79$ & $80+$ \\
\hline Infectious & 6 & 6 & 2 & 2 & 2 & 1 & 1 \\
\hline Neoplasms & 0 & 13 & 9 & 19 & 32 & 23 & 11 \\
\hline Cereberovascular & 0 & 1 & 2 & 4 & 10 & 18 & 20 \\
\hline Diseases of heart & 1 & 3 & 4 & 11 & 25 & 32 & 36 \\
\hline Respiratory & 11 & 10 & 3 & 3 & 5 & 9 & 11 \\
\hline Digestive & 2 & 2 & 2 & 7 & 8 & 5 & 3 \\
\hline MotorVehicle & 0 & 17 & 36 & 14 & 3 & 1 & 0 \\
\hline OtherAccidents & 3 & 19 & 14 & 11 & 3 & 2 & 3 \\
\hline Suicide & 0 & 1 & 11 & 12 & 3 & 1 & 0 \\
\hline Homicide & 0 & 1 & 1 & 1 & 0 & 0 & 0 \\
\hline Other & 75 & 27 & 16 & 16 & 10 & 10 & 15 \\
\hline All Causes & 100 & 100 & 100 & 100 & 100 & 100 & 100 \\
\hline $1990-1995$ & \multicolumn{7}{|c|}{ Age group } \\
\hline Causes of death & $\mathbf{0}$ & $1-14$ & $15-24$ & $25-39$ & $40-64$ & $65-79$ & $80+$ \\
\hline Infectious & 2 & 4 & 1 & 2 & 1 & 1 & 1 \\
\hline Neoplasms & 0 & 15 & 8 & 17 & 41 & 32 & 15 \\
\hline Cereberovascular & 0 & 1 & 1 & 3 & 6 & 11 & 16 \\
\hline Diseases of heart & 2 & 5 & 4 & 9 & 21 & 30 & 36 \\
\hline Respiratory & 3 & 5 & 3 & 3 & 4 & 9 & 12 \\
\hline Digestive & 1 & 1 & 1 & 5 & 7 & 4 & 4 \\
\hline MotorVehicle & 0 & 15 & 38 & 13 & 2 & 1 & 0 \\
\hline OtherAccidents & 3 & 16 & 11 & 8 & 3 & 1 & 2 \\
\hline Suicide & 0 & 1 & 13 & 14 & 4 & 1 & 0 \\
\hline Homicide & 0 & 2 & 2 & 2 & 0 & 0 & 0 \\
\hline Other & 89 & 34 & 18 & 26 & 10 & 10 & 14 \\
\hline All Causes & 100 & 100 & 100 & 100 & 100 & 100 & 100 \\
\hline
\end{tabular}


Robert Bourbeau

the share of infectious and parasitic diseases, and of respiratory diseases, but an increase in the share of external causes of deaths and man-made diseases (cancers, circulatory diseases) during the period from the 1950s to the mid 1990s.

Infectious diseases have dropped in almost every age-group and constitute a very small part of total deaths (less than 4 percent) at the end of the period. Respiratory diseases also dropped below age 40 but slightly increased above age 40.

As a proportion of total deaths, external causes are mostly limited to the 1-39 year old group. Particularly, a large increase in the share of deaths due to motorvehicle accidents, suicides, and homicides was observed from the 1950s to the early 1990s. Neoplasms increased as a proportion of total deaths during these years, up to $41 \%$ in the $40-69$ age group. The proportion of death due to diseases of the heart remained to the same level, but the share of total deaths due to cerebrovascular diseases was reduced.

So, the changes in the distribution of deaths from the 1950s to the mid 1990s were consistent with the epidemiological transition theory. This has already been shown for Canada (Nagnur and Nadrodski, 1990; Bah and Rajulton, 1991).

\section{Trends in Rate Ratios for Total and Cause-specific Mortality}

Figures 5.1 to 5.12 show trends in rate ratios for total and cause-specific mortality (both sexes combined). Figure 5.1 shows the trends in rate ratios by age for total mortality. Canadian mortality rates were lower than the aggregate during the fifties for all age groups, as shown in table 4a. Then there was a deterioration in almost all age groups, but more clearly for the 15-24, 25-39, 114 and 0 age groups.

The other figures (5.2 to 5.12) illustrate that the changes in cause-specific mortality were varied, both in terms of levels and trends. In fact, the relative position of Canada improved for some causes: cancers (except for the 40-79 age group), diseases of the heart, cerebrovascular diseases, and motor vehicle accidents. However, an increase in rate ratios relative to other developed countries was obvious for suicide below age 65 . There was also some increase in rate ratios for infectious diseases at ages 15 to 24 , especially in the $1980 \mathrm{~s}$ (AIDS?), for cancers (40-79), for respiratory and digestive diseases and for the residual category (all other diseases). 
Canadian Mortality in Perspective: A Comparison with the United States and other Developed Countries

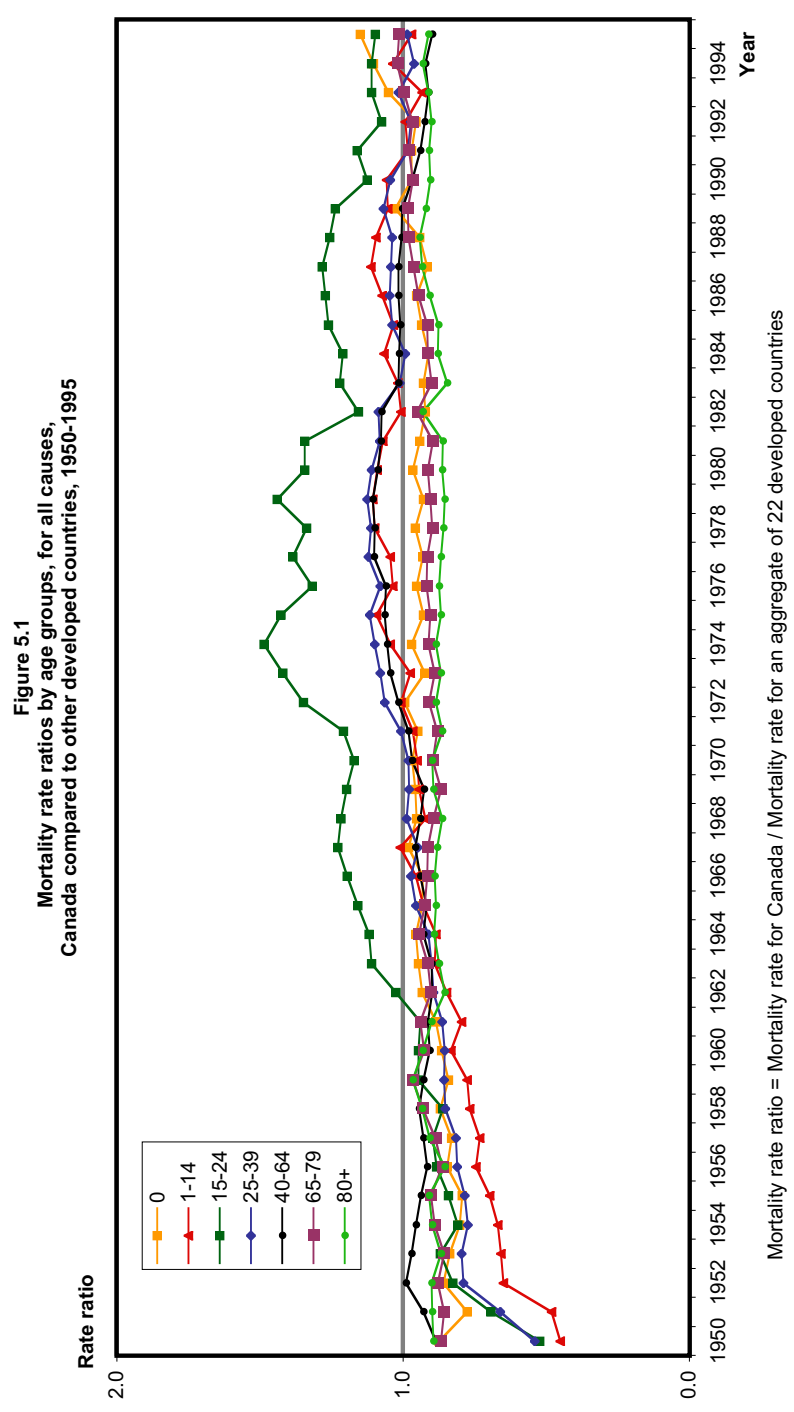


Robert Bourbeau

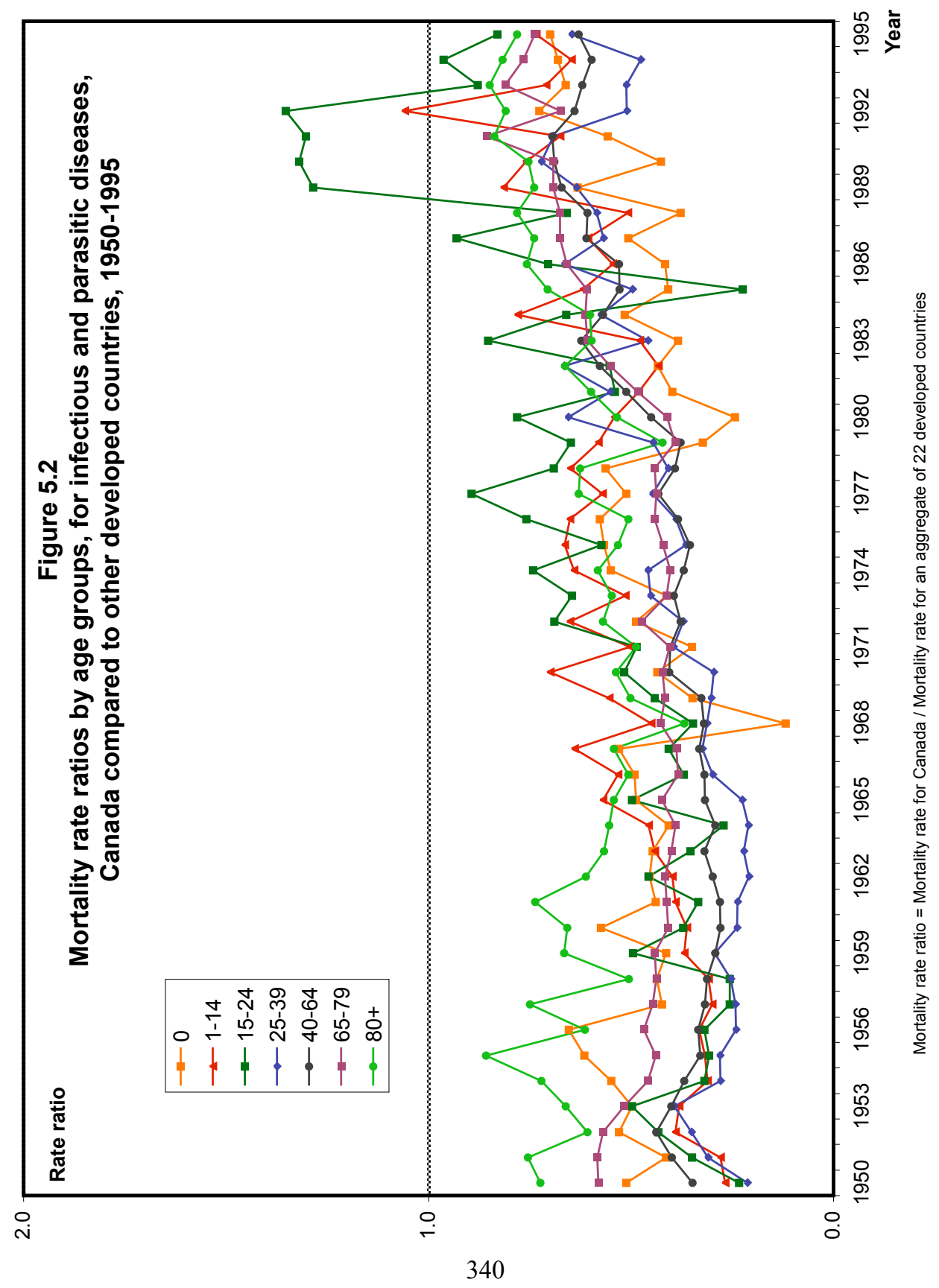


Canadian Mortality in Perspective:

A Comparison o the United States and other Developed Countries

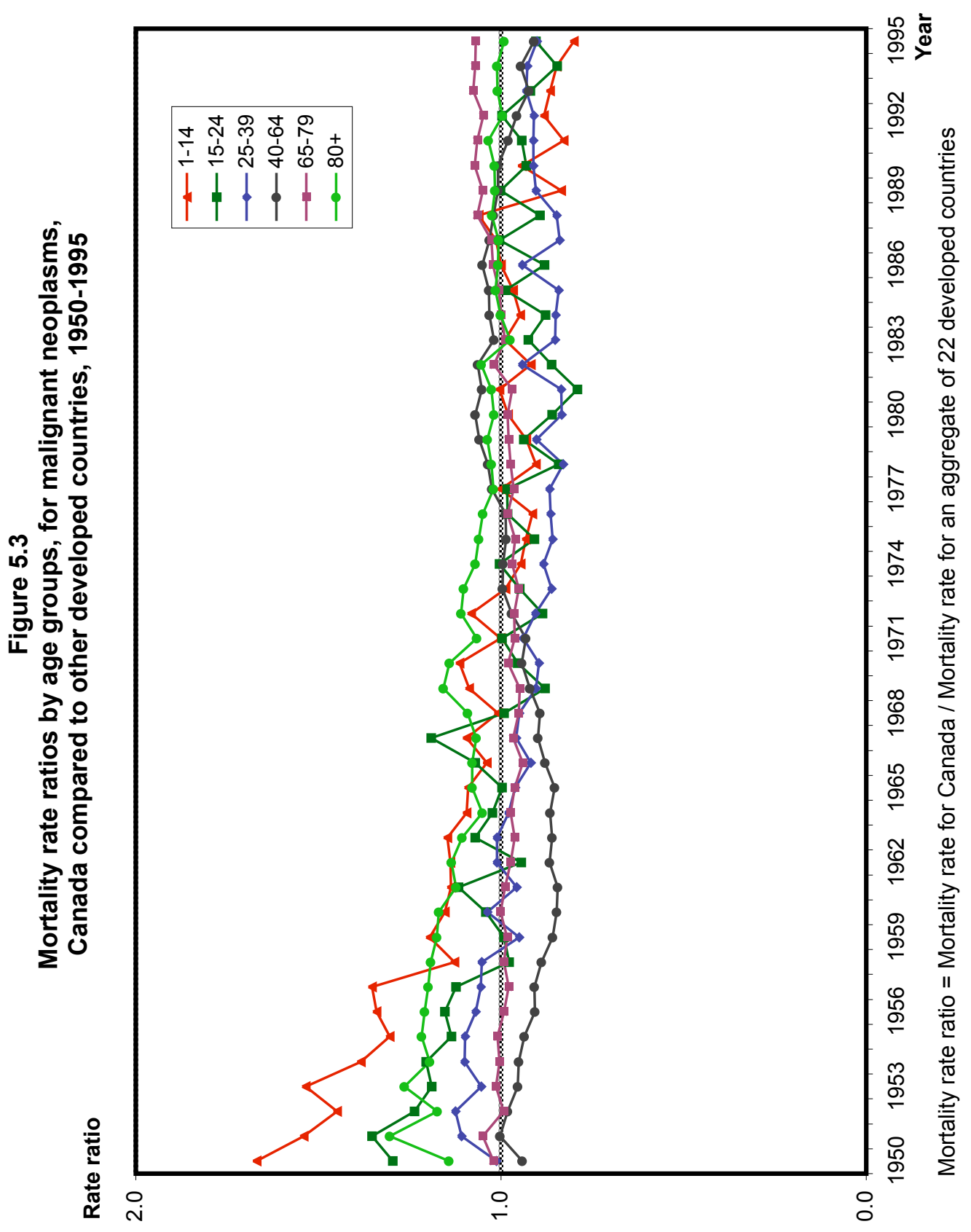




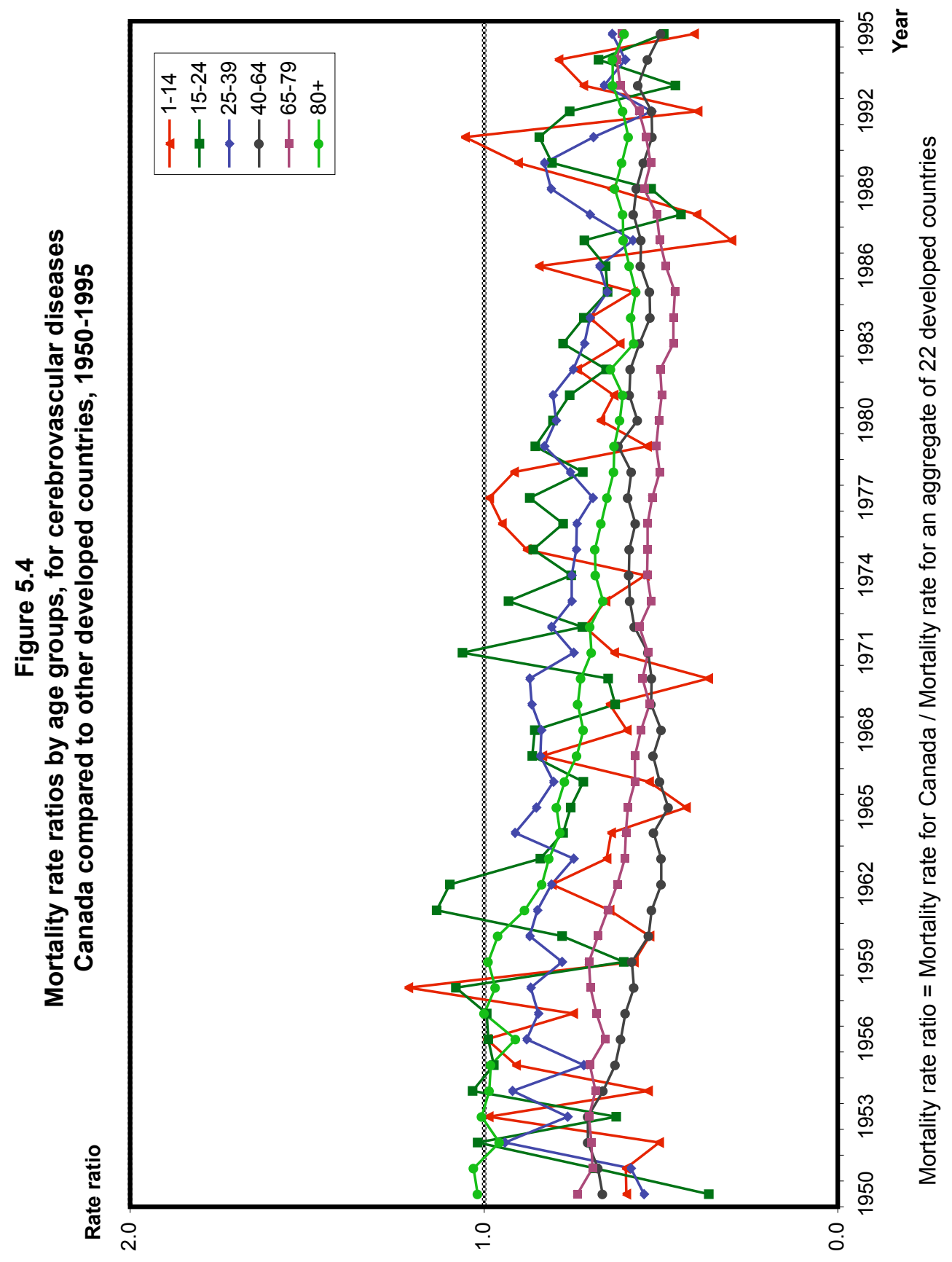


Canadian Mortality in Perspective:

A Comparison o the United States and other Developed Countries

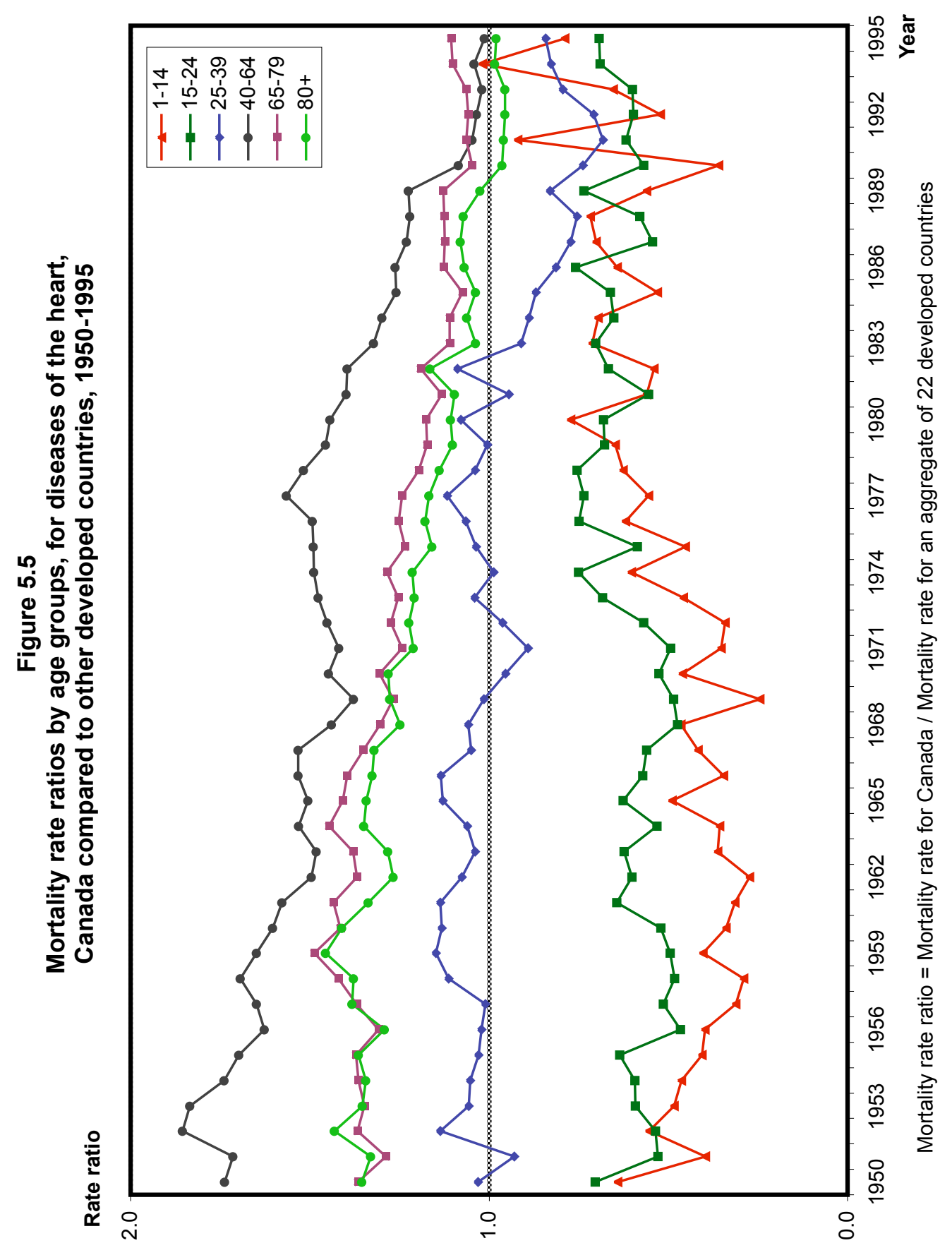




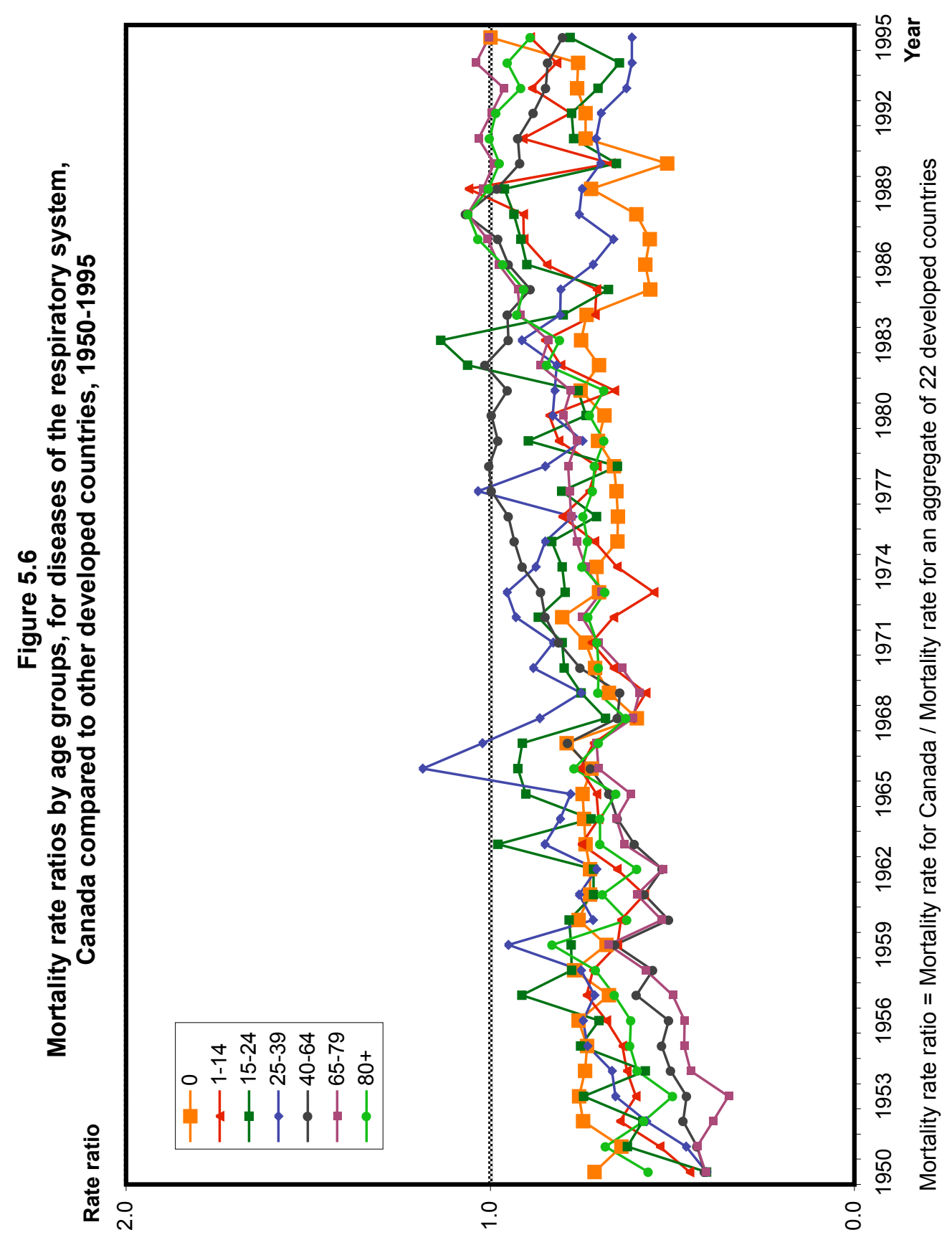


Canadian Mortality in Perspective:

A Comparison o the United States and other Developed Countries

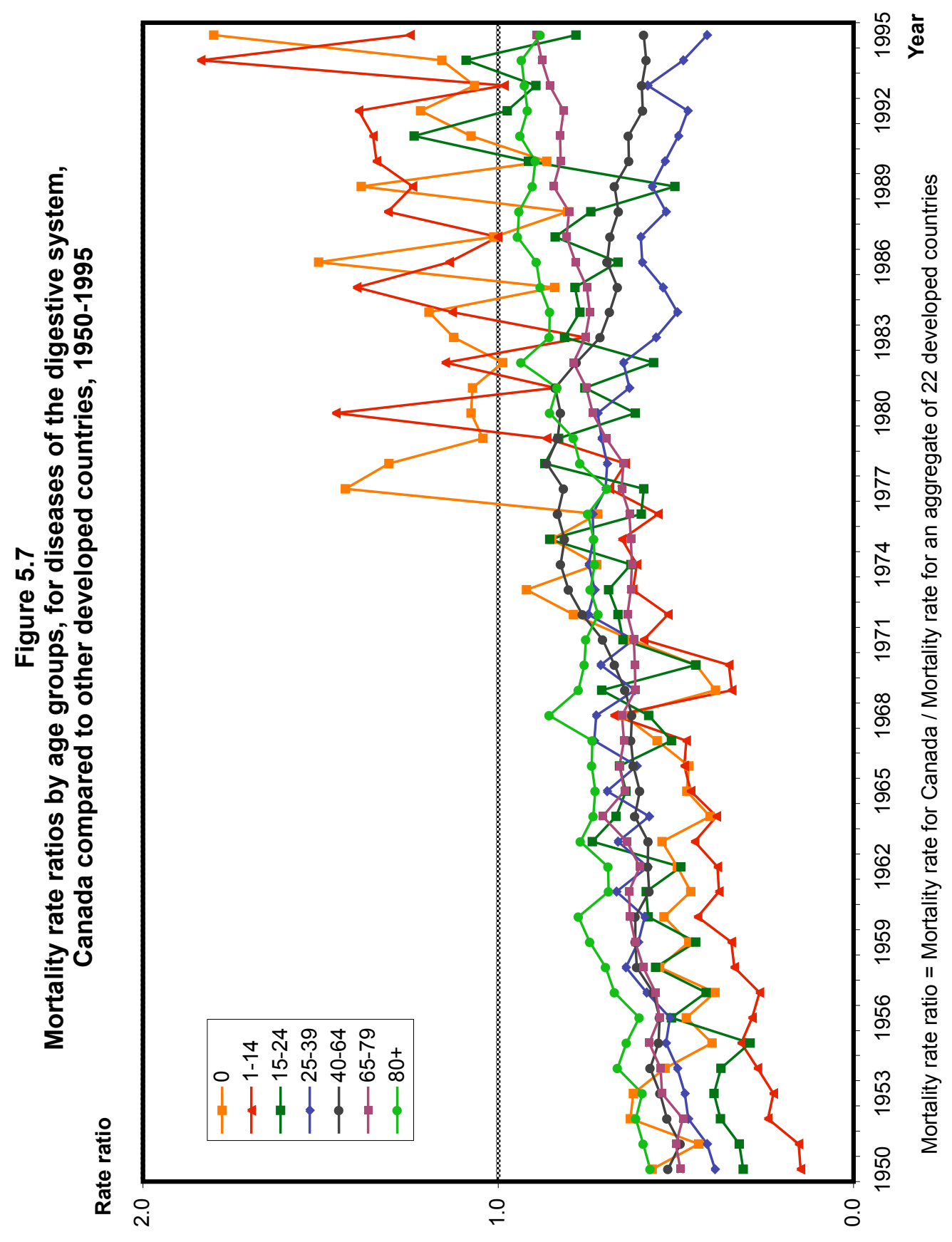




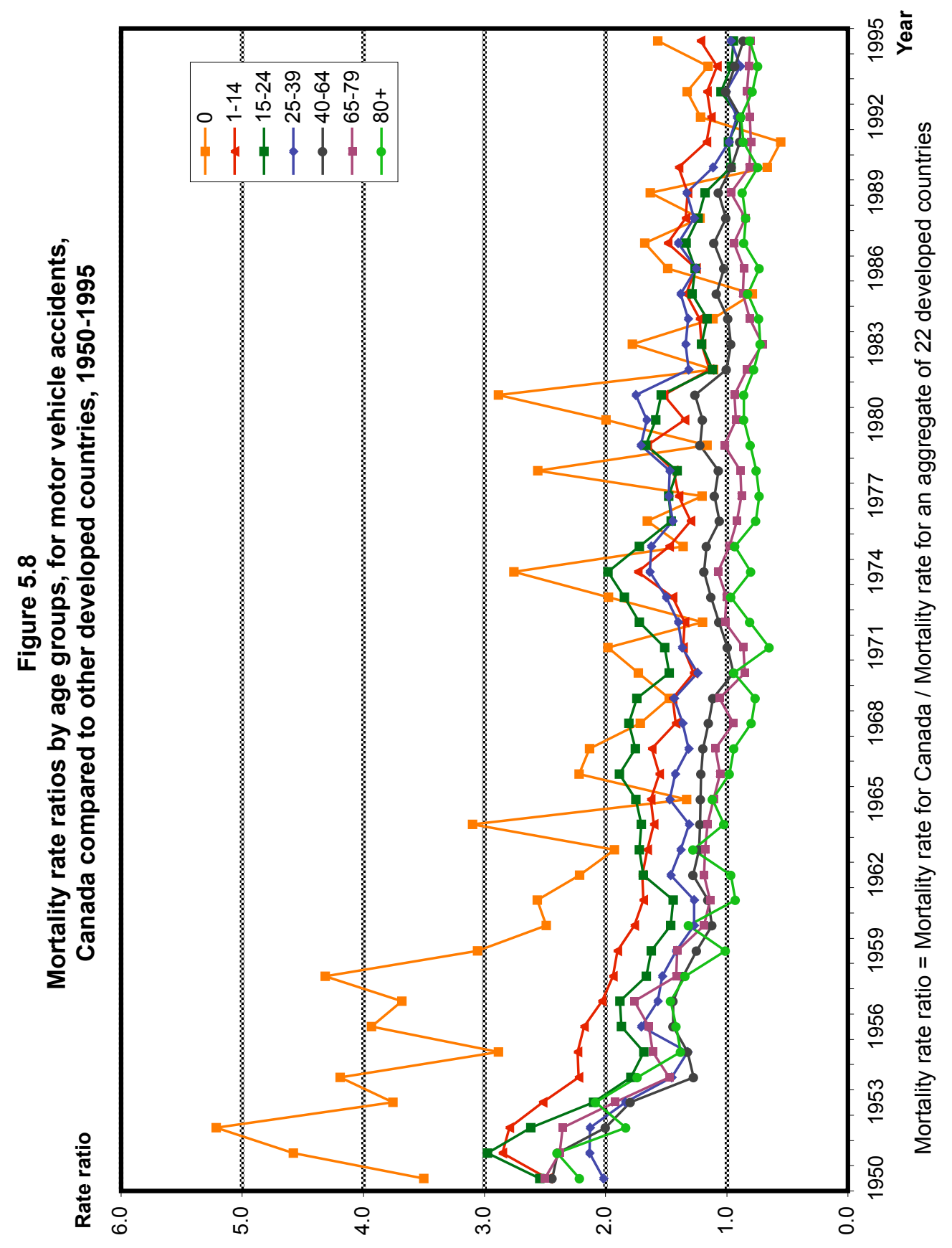


Canadian Mortality in Perspective:

A Comparison o the United States and other Developed Countries

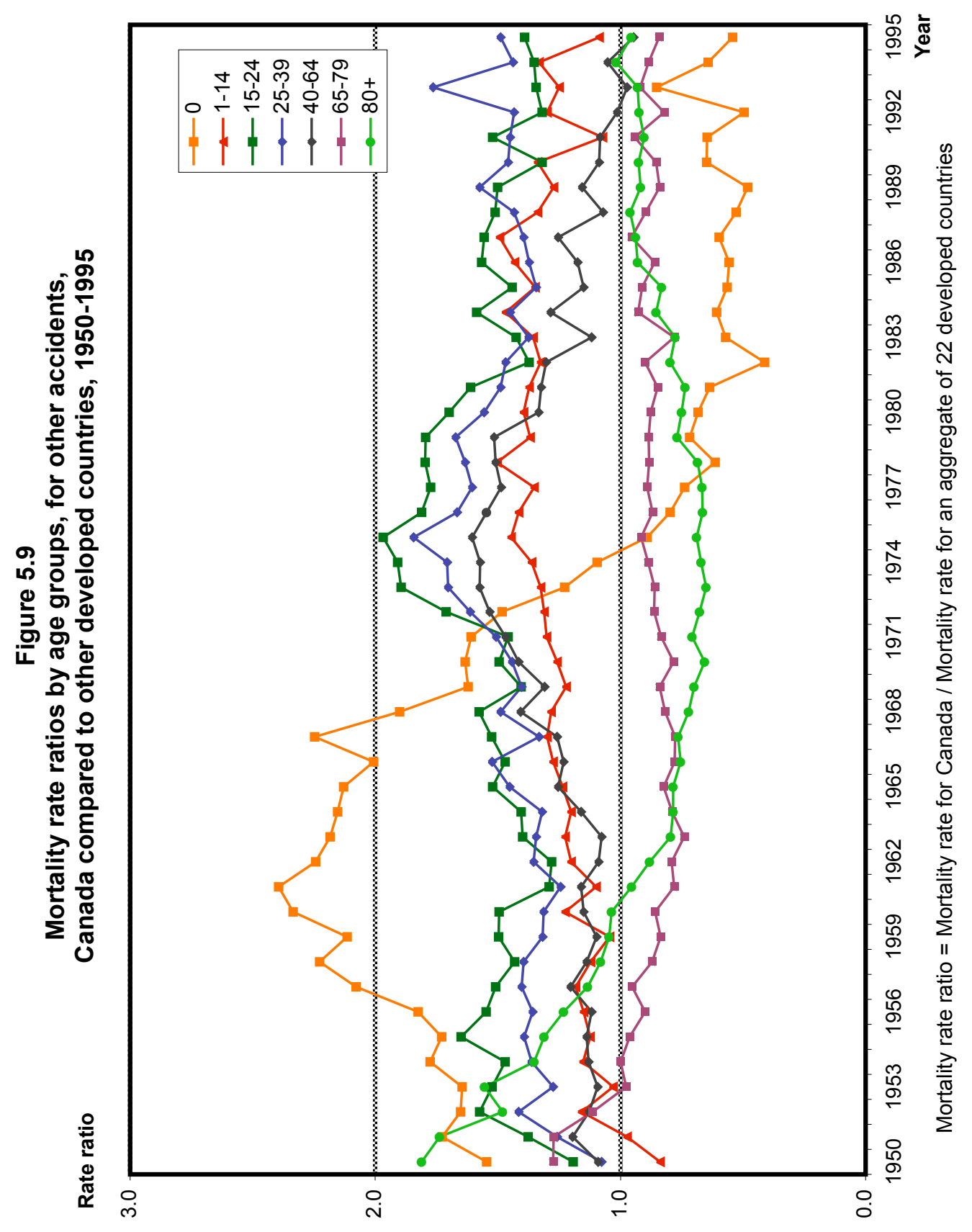




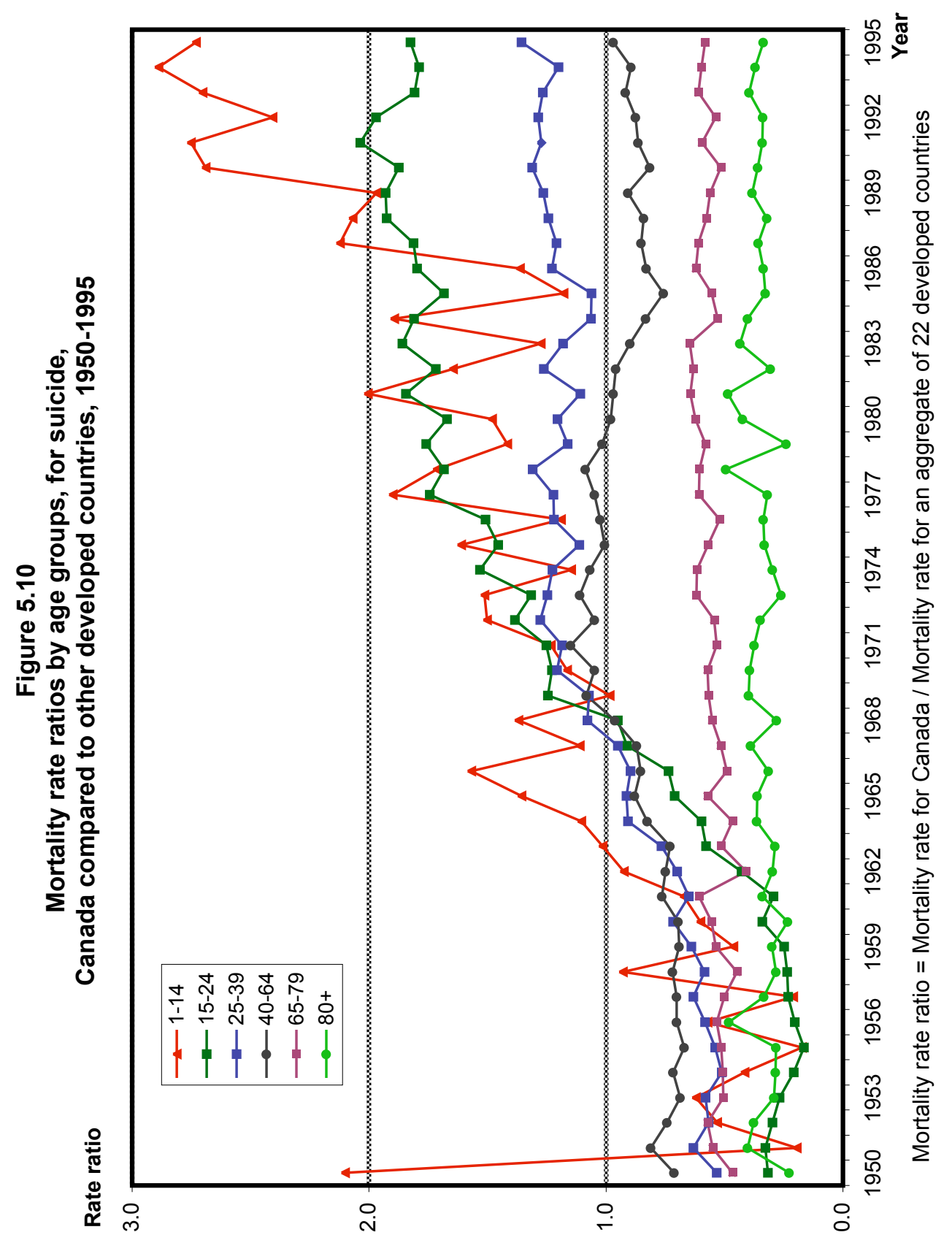


Canadian Mortality in Perspective:

A Comparison o the United States and other Developed Countries

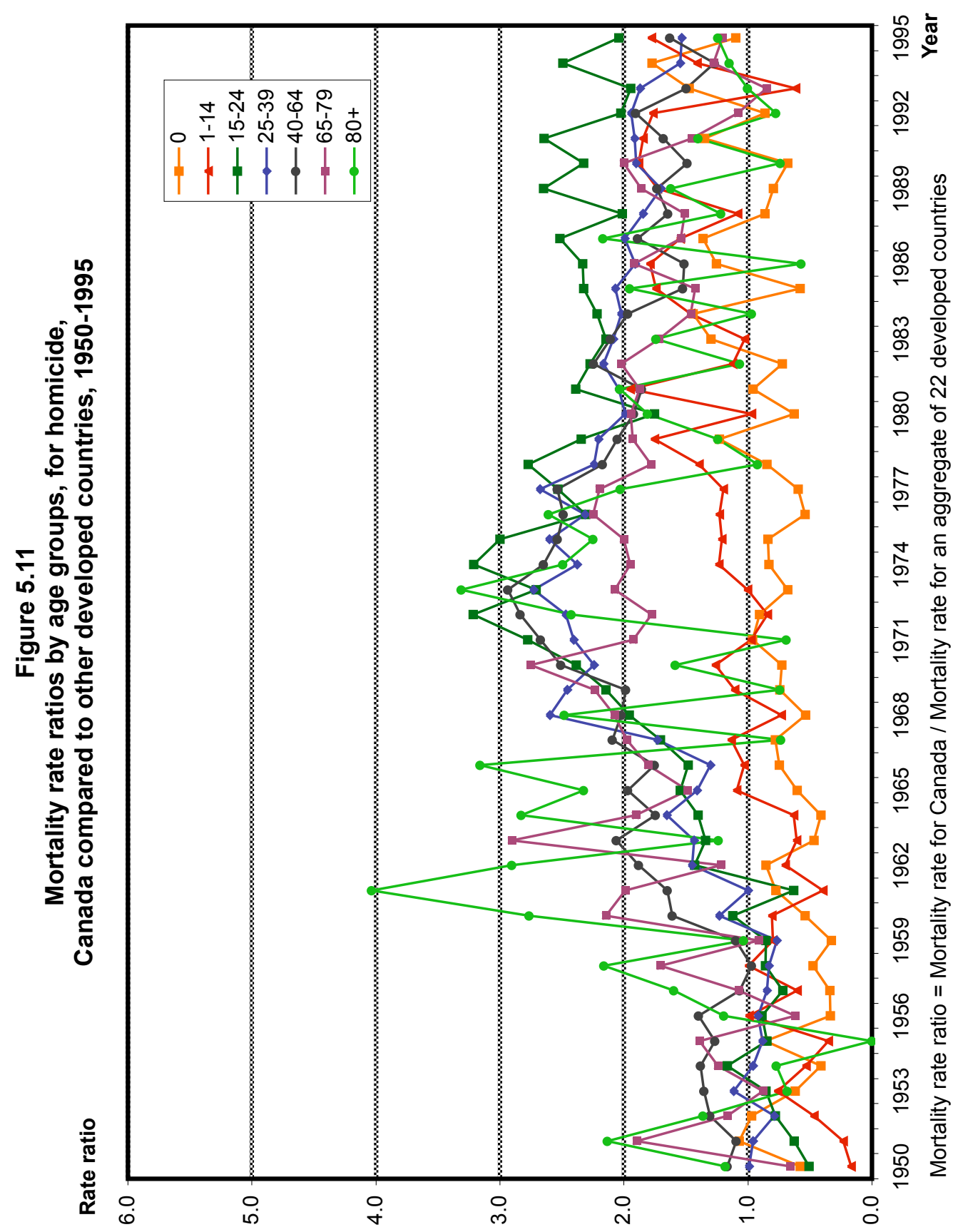




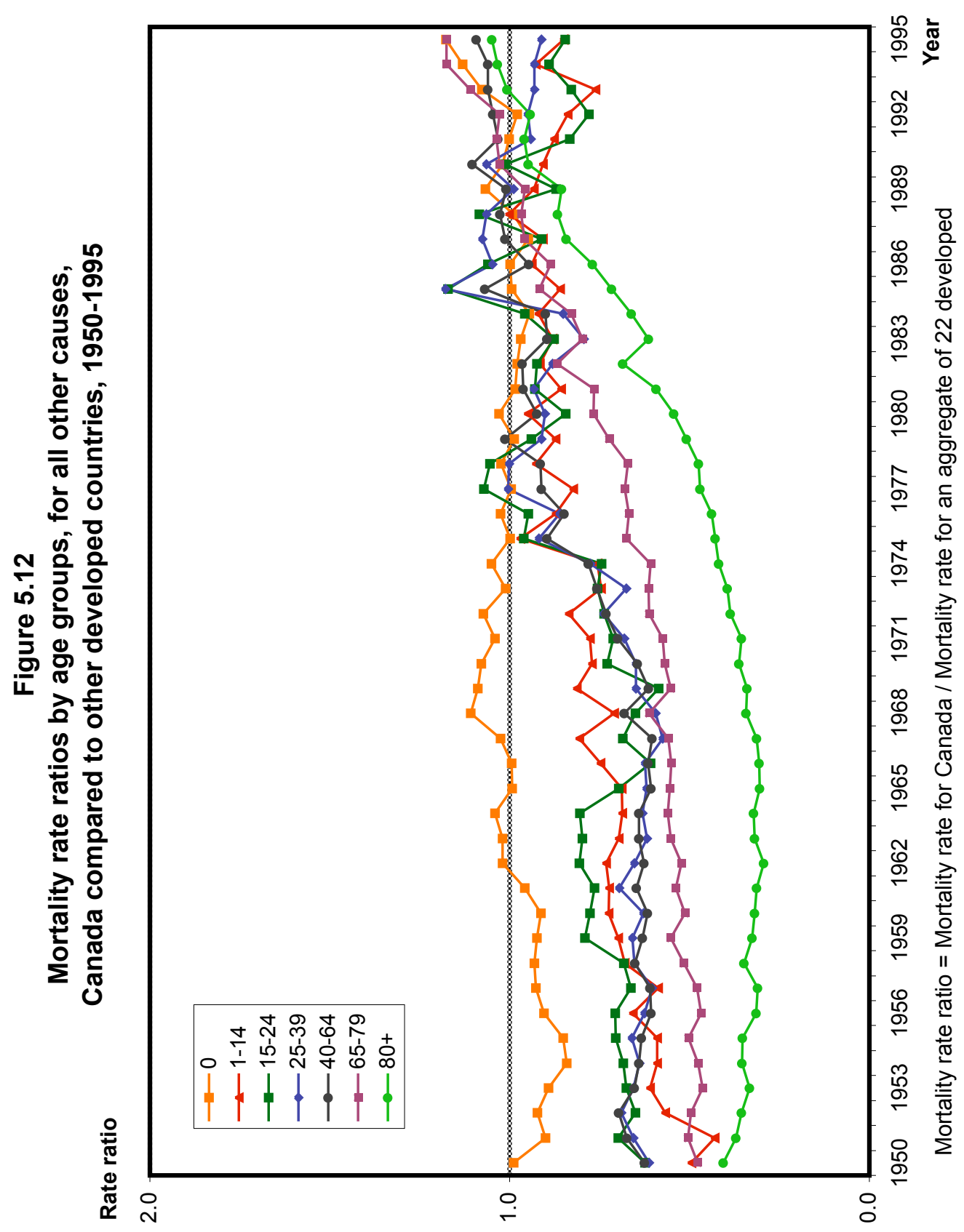


Canadian Mortality in Perspective:

A Comparison with the United States and other Developed Countries

\section{Decomposition for Canada}

Table 6 presents the results of the decomposition for each age group and each sex, for Canada.

These detailed results are summarised in tables 7 and 8 .

\section{Comparisons with the United States}

A summary table (table 7) shows the results for total mortality, comparing Canada and the USA.

In general, the changes in Canadian mortality rate ratios from the 1950 s to the mid 1990s were important but quite smaller than those in the USA (columns 5 and 6). Also, the shift in the distribution of causes of deaths played a major role in overall changes in the relative standing of Canadian mortality (column 3). This shift did not favour Canada and contributed to a deterioration of Canada's relative ranking. For both sexes, for ages 1 to 39, the shift was more important than the change in the rate ratios and was mainly responsible for the deterioration of Canadian mortality at these ages.

Canada has experienced a quite different evolution of relative rates compared to the U.S. Wilmoth (1998) has shown that the US experienced an important increase in mortality rate ratios compared to other developed countries since the 1950 s and that this increase was mostly related to the increase in the causespecific mortality rate ratios and not to the changes in the distribution of deaths by cause of death: "The United States is doing worse and worse in terms of total mortality because, on the whole, it is doing worse and worse in terms of specific causes of death" (Wilmoth, 1998, p 8).

For Canadian women, the changes in rate ratios were more important below age 40 and the shift in the distribution of causes of death was a major factor in this increase in rate ratios. Rate ratios have declined for only two causes of deaths: motor-vehicle accidents and cancers. These declines were offset by increases in rate ratios for infectious diseases, suicide and other causes. Above age 40, changes in total rate ratios were smaller, and the two components had an equal contribution to these changes. The large reduction in rate ratios for the diseases of the heart and cerebrovascular diseases were more than counterbalanced by increases in relative rates for other causes, respiratory diseases and cancers. For women above age 80 , the main factors explaining the decrease in total and cause-specific relative rates were a decrease in rate ratios for the diseases of the heart, for cerebrovascular diseases and for cancers (Table 6). However, these decreases in rate ratios were partly offset by an increase in rate ratios for residual causes. 
Robert Bourbeau

Table 6

Decomposition of Total Changes in Mortality Rate Ratios by Age Group, Sex and Causes of Death, 1950-1959 to 1990-1995 for Canada

Aggregate without the USA

\begin{tabular}{l||cc||cc||cc}
\hline \multicolumn{1}{c||}{\begin{tabular}{c}
\multicolumn{1}{c||}{ Age 0 } \\
Causes of death
\end{tabular}} & \multicolumn{2}{c||}{ Changes in Rate Ratios } & \multicolumn{2}{c||}{ Changes in Distribution } & \multicolumn{2}{c}{ Total Changes } \\
\hline \hline & Women & Men & Women & Men & Women & Men \\
\hline Infectious & \multicolumn{1}{|c||}{} & & & & & -1 \\
Neoplasms & 0 & 0 & -1 & -1 & -1 & 0 \\
Cereberovascular & 0 & 0 & 0 & 0 & 0 & 0 \\
Diseases of heart & 0 & 1 & 1 & 0 & 0 & 1 \\
Respiratory & 0 & 0 & -11 & -10 & -10 & -10 \\
Digestive & 2 & 4 & -6 & -8 & -4 & -4 \\
MotorVehicle & -1 & -1 & 1 & 1 & 0 & 0 \\
OtherAccidents & -2 & -3 & 1 & 1 & -1 & -1 \\
Suicide & $\mathrm{n} / \mathrm{a}$ & $\mathrm{n} / \mathrm{a}$ & $\mathrm{n} / \mathrm{a}$ & $\mathrm{n} / \mathrm{a}$ & $\mathrm{n} / \mathrm{a}$ & $\mathrm{n} / \mathrm{a}$ \\
Homicide & 0 & 0 & 0 & 0 & 0 & 0 \\
Other & 15 & 9 & 22 & 21 & 37 & 30 \\
All Causes & 16 & 11 & 7 & 5 & 23 & 16 \\
& & & & & & \\
\hline
\end{tabular}

\begin{tabular}{l||cc||cc||cc}
\hline \multicolumn{1}{c||}{$\begin{array}{c}\text { Age 1-14 } \\
\text { Causes of death }\end{array}$} & \multicolumn{2}{c||}{$\begin{array}{c}\text { Changes in Rate Ratios } \\
\text { Women }\end{array}$} & Men & \multicolumn{2}{c||}{ Changes in Distribution } & \multicolumn{2}{c}{ Total Changes } \\
Women & Men & Women & Men \\
\hline \hline & & & & & & \\
Infectious & 8 & 4 & -12 & -8 & -4 & -5 \\
Neoplasms & -5 & -5 & 14 & 12 & 9 & 7 \\
Cereberovascular & 0 & 0 & 1 & 1 & 1 & 0 \\
Diseases of heart & 1 & 1 & 1 & 1 & 2 & 1 \\
Respiratory & 3 & 1 & -8 & -7 & -5 & -5 \\
Digestive & 8 & 9 & -10 & -11 & -2 & -2 \\
MotorVehicle & -10 & -10 & 19 & 18 & 9 & 7 \\
OtherAccidents & 2 & 2 & 4 & 3 & 6 & 5 \\
Suicide & 1 & 1 & 1 & 2 & 2 & 3 \\
Homicide & 1 & 1 & 2 & 1 & 3 & 2 \\
Other & 8 & 7 & 11 & 8 & 19 & 15 \\
All Causes & 19 & 11 & 22 & 18 & 41 & 29 \\
& & & & & & \\
\hline
\end{tabular}

\begin{tabular}{|c|c|c|c|c|c|c|}
\hline \multirow{2}{*}{$\begin{array}{c}\text { Age 15-24 } \\
\text { Causes of death }\end{array}$} & \multicolumn{2}{|c|}{ Changes in Rate Ratios } & \multicolumn{2}{|c|}{ Changes in Distribution } & \multicolumn{2}{|c|}{ Total Changes } \\
\hline & Women & Men & Women & Men & Women & Men \\
\hline Infectious & 14 & 5 & -22 & -10 & -8 & -5 \\
\hline Neoplasms & -2 & -1 & 8 & 2 & 6 & 1 \\
\hline Cereberovascular & 0 & 0 & 1 & 0 & 0 & 0 \\
\hline Diseases of heart & 1 & 0 & -3 & -1 & -2 & -1 \\
\hline Respiratory & 0 & 0 & -1 & -1 & -1 & -1 \\
\hline Digestive & 2 & 2 & -3 & -3 & -1 & -1 \\
\hline MotorVehicle & -25 & -24 & 51 & 33 & 26 & 9 \\
\hline OtherAccidents & 2 & -3 & 4 & -11 & 5 & -14 \\
\hline Suicide & 14 & 22 & 0 & 2 & 14 & 24 \\
\hline Homicide & 2 & 2 & 2 & 1 & 5 & 3 \\
\hline Other & 4 & 3 & 0 & 2 & 4 & 5 \\
\hline All Causes & 13 & 5 & 36 & 12 & 49 & 18 \\
\hline Age 25-39 & \multicolumn{2}{|c|}{ Changes in Rate Ratios } & \multicolumn{2}{|c|}{ Changes in Distribution } & \multicolumn{2}{|c|}{ Total Changes } \\
\hline Causes of death & Women & Men & Women & Men & Women & Men \\
\hline Infectious & 4 & 3 & -11 & -8 & -7 & -5 \\
\hline Neoplasms & -3 & -2 & 16 & 3 & 13 & 1 \\
\hline Cereberovascular & 0 & 0 & 1 & 0 & 1 & 0 \\
\hline Diseases of heart & 1 & -6 & -4 & 0 & -3 & -6 \\
\hline Respiratory & 1 & 0 & -1 & -1 & 0 & -1 \\
\hline Digestive & 1 & 0 & -1 & -1 & 0 & -1 \\
\hline MotorVehicle & -5 & -7 & 12 & 6 & 7 & -1 \\
\hline OtherAccidents & 2 & 2 & 2 & -6 & 4 & -4 \\
\hline Suicide & 5 & 8 & 4 & 7 & 9 & 15 \\
\hline Homicide & 1 & 1 & 2 & 1 & 2 & 2 \\
\hline Other & 4 & 8 & -2 & 10 & 2 & 18 \\
\hline All Causes & 10 & 7 & 19 & 10 & 28 & 17 \\
\hline
\end{tabular}


Canadian Mortality in Perspective: A Comparison with the United States and other Developed Countries

Table 6 (Continued)

Decomposition of Total Changes in Mortality Rate Ratios by Age Group, Sex and Causes of Death, 1950-1959 to 1990-1995 for Canada

Aggregate without the USA

\begin{tabular}{|c|c|c|c|c|c|c|}
\hline \multirow{2}{*}{$\begin{array}{c}\text { Age 40-64 } \\
\text { Causes of death }\end{array}$} & \multicolumn{2}{|c|}{ Changes in Rate Ratios } & \multicolumn{2}{|c|}{ Changes in Distribution } & \multicolumn{2}{|c|}{ Total Changes } \\
\hline & Women & Men & Women & Men & Women & Men \\
\hline $\begin{array}{l}\text { Infectious } \\
\text { Neoplasms } \\
\text { Cereberovascular } \\
\text { Diseases of heart } \\
\text { Respiratory } \\
\text { Digestive } \\
\text { MotorVehicle } \\
\text { OtherAccidents } \\
\text { Suicide } \\
\text { Homicide } \\
\text { Other } \\
\text { All Causes }\end{array}$ & $\begin{array}{c}1 \\
3 \\
-1 \\
-6 \\
2 \\
1 \\
-1 \\
0 \\
1 \\
0 \\
4 \\
4\end{array}$ & $\begin{array}{c}1 \\
1 \\
-1 \\
-19 \\
2 \\
0 \\
-1 \\
0 \\
1 \\
0 \\
5 \\
-12\end{array}$ & $\begin{array}{c}-3 \\
22 \\
-5 \\
-5 \\
0 \\
-1 \\
1 \\
0 \\
1 \\
0 \\
-4 \\
6\end{array}$ & $\begin{array}{c}-3 \\
13 \\
-3 \\
2 \\
-2 \\
0 \\
0 \\
-1 \\
1 \\
0 \\
-2 \\
6\end{array}$ & $\begin{array}{c}-1 \\
24 \\
-6 \\
-11 \\
2 \\
0 \\
0 \\
0 \\
1 \\
0 \\
0 \\
11\end{array}$ & $\begin{array}{c}-2 \\
14 \\
-3 \\
-17 \\
0 \\
0 \\
-1 \\
-1 \\
2 \\
0 \\
4 \\
-6\end{array}$ \\
\hline Age 65-79 & \multicolumn{2}{|c|}{ Changes in Rate Ratios } & \multicolumn{2}{|c|}{ Changes in Distribution } & \multicolumn{2}{|c|}{ Total Changes } \\
\hline Causes of death & Women & Men & Women & Men & Women & Men \\
\hline $\begin{array}{l}\text { Infectious } \\
\text { Neoplasms } \\
\text { Cereberovascular } \\
\text { Diseases of heart } \\
\text { Respiratory } \\
\text { Digestive } \\
\text { MotorVehicle } \\
\text { OtherAccidents } \\
\text { Suicide } \\
\text { Homicide } \\
\text { Other } \\
\text { All Causes }\end{array}$ & $\begin{array}{l}0 \\
3 \\
-3 \\
-8 \\
5 \\
2 \\
0 \\
0 \\
0 \\
0 \\
8 \\
6\end{array}$ & $\begin{array}{c}0 \\
1 \\
-1 \\
-9 \\
4 \\
1 \\
-1 \\
0 \\
0 \\
0 \\
8 \\
6\end{array}$ & $\begin{array}{c}0 \\
15 \\
-5 \\
-1 \\
0 \\
0 \\
0 \\
0 \\
0 \\
0 \\
-4 \\
5\end{array}$ & $\begin{array}{c}-1 \\
16 \\
-5 \\
1 \\
0 \\
-1 \\
0 \\
0 \\
0 \\
0 \\
-6 \\
5\end{array}$ & $\begin{array}{c}0 \\
18 \\
-8 \\
-9 \\
5 \\
1 \\
0 \\
0 \\
0 \\
0 \\
4 \\
11\end{array}$ & $\begin{array}{c}-1 \\
17 \\
-5 \\
-8 \\
5 \\
1 \\
0 \\
0 \\
0 \\
0 \\
2 \\
10\end{array}$ \\
\hline Age 80+ & \multicolumn{2}{|c|}{ Changes in Rate Ratios } & \multicolumn{2}{|c|}{ Changes in Distribution } & \multicolumn{2}{|c|}{ Total Changes } \\
\hline Causes of death & Women & Men & Women & Men & Women & Men \\
\hline $\begin{array}{l}\text { Infectious } \\
\text { Neoplasms } \\
\text { Cereberovascular } \\
\text { Diseases of heart } \\
\text { Respiratory } \\
\text { Digestive } \\
\text { MotorVehicle } \\
\text { OtherAccidents } \\
\text { Suicide } \\
\text { Homicide } \\
\text { Other } \\
\text { All Causes }\end{array}$ & $\begin{array}{c}0 \\
-2 \\
-7 \\
-15 \\
3 \\
1 \\
0 \\
-1 \\
0 \\
0 \\
14 \\
-7\end{array}$ & $\begin{array}{c}0 \\
-2 \\
-4 \\
-11 \\
4 \\
1 \\
0 \\
0 \\
0 \\
0 \\
13 \\
0\end{array}$ & $\begin{array}{c}0 \\
6 \\
1 \\
5 \\
0 \\
0 \\
0 \\
0 \\
0 \\
0 \\
-8 \\
5\end{array}$ & $\begin{array}{c}0 \\
12 \\
-1 \\
2 \\
3 \\
0 \\
0 \\
0 \\
0 \\
0 \\
-11 \\
5\end{array}$ & $\begin{array}{c}0 \\
4 \\
-6 \\
-10 \\
3 \\
1 \\
0 \\
-1 \\
0 \\
0 \\
6 \\
-2\end{array}$ & $\begin{array}{c}0 \\
9 \\
-5 \\
-9 \\
7 \\
1 \\
0 \\
0 \\
0 \\
0 \\
2 \\
5\end{array}$ \\
\hline
\end{tabular}


Robert Bourbeau

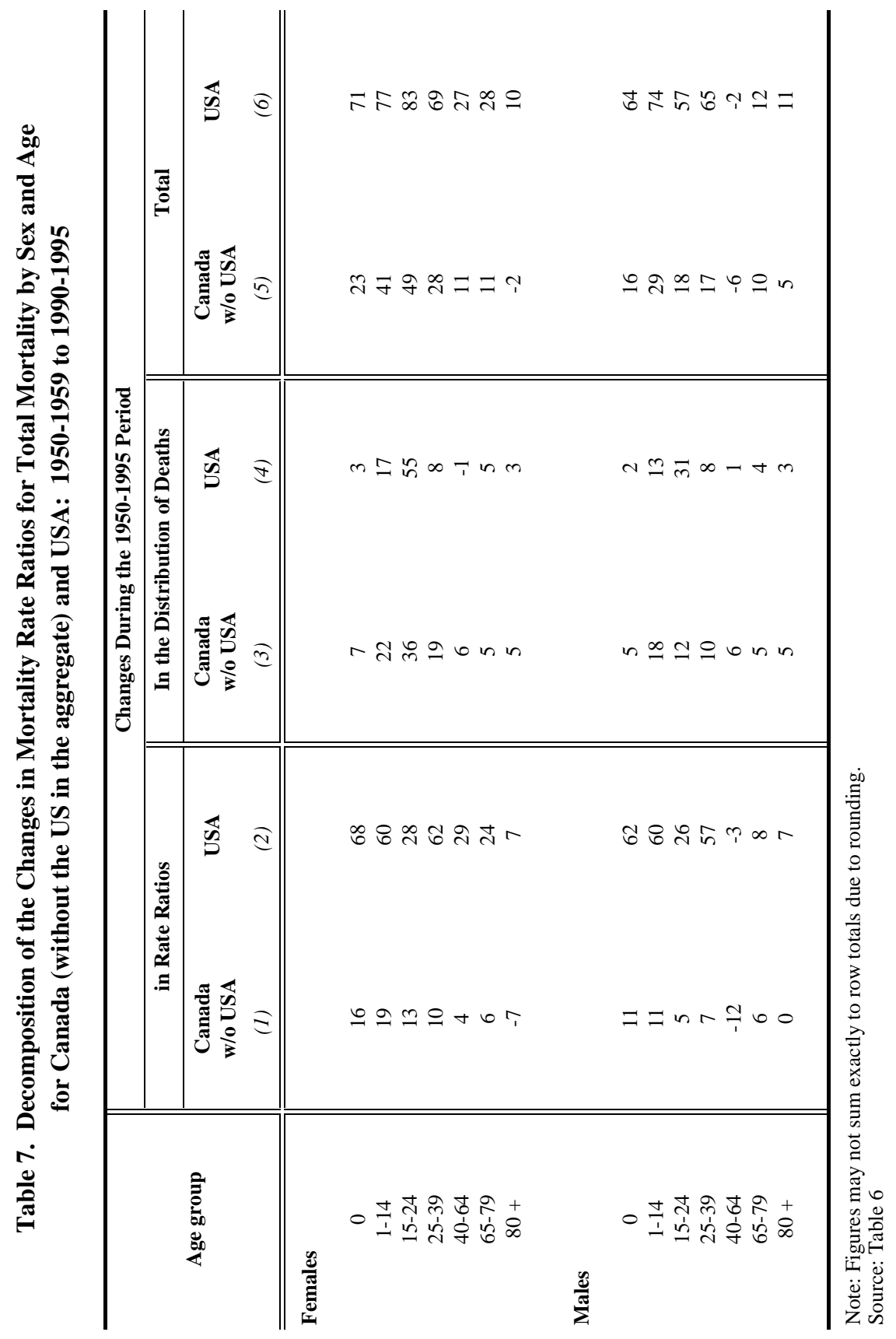


Canadian Mortality in Perspective:

A Comparison with the United States and other Developed Countries

For men, changes were smaller than for women but the pattern was similar. Below age 40 , the large decreases in rate ratios for motor vehicle accidents were partly offset by increases in rate ratios for suicide, for infectious diseases and for other diseases. For men aged 40-64, the main factor explaining the improvement in Canada's ranking relative to other countries was a decrease in rate ratios for the diseases of the heart. These diseases also showed a decrease in rate ratios for men above age 65 , but an increase in rate ratios for residual causes more than offset that decrease.

\section{Causes of Death and their Contribution to the Changes in Rate Ratios for Total Mortality}

The results of the decomposition can be summarised by the following table 8 . Entries in this table describe the general direction of changes in both rate ratios and the proportion of the total deaths for the major cause categories considered here.

Some causes contributed to increasing rate ratios for total mortality over the period from the 1950s to the mid 1990s both by increases in their cause-specific rate ratios and by increases in their shares of total mortality: suicide, respiratory diseases above age 40, cancers for ages 40-79, residual causes below age 40, and homicide (1-39) (upper left cell).

Other causes contributed to increases in total rate ratios only by an increase in their cause-specific rate ratios, but this effect was balanced to some degree by decrease in their share of total mortality: infectious diseases below age 65, residual causes above age 40, digestive diseases (lower left cell).

A third group has decreasing cause-specific rate ratios but an increasing share of total mortality: motor vehicle accidents, diseases of the heart (above age 40 for men and above age 80 for women), cerebrovascular above age 80 for women, and cancers (below age 40 and above age 80 ) (upper right cell).

The last group has both declining cause-specific rate ratios and a decreasing share of total deaths: diseases of the heart (for some age groups), and cerebrovascular diseases above age 40 (lower right cell).

\section{Changes in Cause-specific Rate Ratios}

If we focus on the effects of changes in cause-specific rate ratios, several points are worth noting.

For infants, increases in the rate ratios for the large residual category (all other causes) were mainly responsible for the deterioration of Canadian mortality 
Table 8

Changes in Mortality Rate Ratios and in the Proportion of Total Mortality by Cause of Death, 1950s to Mid-1990s (without USA in the aggregate)

\begin{tabular}{|c|c|c|}
\hline \multirow{2}{*}{$\begin{array}{l}\text { Change in Proportion } \\
\text { of Total Mortality } \\
\text { 1950s to 1990s }\end{array}$} & \multicolumn{2}{|c|}{ Changes in Mortality Rate Ratios - 1950s to 1990s } \\
\hline & Increase & Decrease \\
\hline Increase & $\begin{array}{l}\text { Suicide (1-39) } \\
\text { Cancers (40-79) } \\
\text { Respiratory (40+) } \\
\text { Residual causes (0-39) } \\
\text { Homicide (1-39)* }\end{array}$ & $\begin{array}{l}\text { Motor Vehicle } \\
\text { Diseases of heart }(40-79 \mathrm{M}, 80+) \\
\text { Cerebrovascular }(80+\mathrm{W}) \\
\text { Cancers }(1-39,80+)\end{array}$ \\
\hline Decrease & $\begin{array}{l}\text { Infectious }(0-64) \\
\text { Residual causes }(40+) \\
\text { Digestive } \\
\text { Diseases of heart }(25-39 \mathrm{~W}) \\
\text { Respiratory }(0-39)^{* *}\end{array}$ & $\begin{array}{l}\text { Cerebrovascular }(40+\mathrm{M} ; 40-79 \mathrm{~W}) \\
\text { Diseases of heart }(25-39 \mathrm{M} ; 40-79 \mathrm{~W})\end{array}$ \\
\hline
\end{tabular}

* Changes in mortality rate ratios for homicide were very small, and they had a small contribution

to changes in rate ratio for total mortality

** Increases in rate ratios for respiratory diseases were very small.

( ) Age intervals 


\section{Canadian Mortality in Perspective: \\ A Comparison with the United States and other Developed Countries}

during the first year of life. A more detailed analysis should be interesting for this group, because diseases of infancy and childbirth were substantial in this category.

For children and adolescents, increases in rate ratios for infectious and parasitic diseases, digestive diseases and residual causes were responsible for the deterioration of Canadian position relative to other developed countries, although there was an important decrease in rate ratios for motor vehicle accidents and for cancers.

Young adults showed the most contrasting results: there was a form of trade-off between motor-vehicle accidents (large decrease in rate ratios) and suicides (large increase in rate ratios), and an increase in rate ratios for infectious and parasitic diseases, probably due to AIDS. These effects resulted in an overall increase in Canadian mortality rate ratios for the 15-24 group.

The group 25-34 experienced an increase in rate ratios, due to the contribution of almost every group of causes, except for motor vehicle accidents and cancers that showed some decrease. Suicide played an important role in the increase in Canadian mortality rate ratios for young adults. There was no indication of an adverse effect of the AIDS epidemic in this age group as was the case for the United States. Another important difference with the United States is that the changes in rate ratios due to homicides were negligible in the Canadian standing.

Above age 40, the effect of changes vis-à-vis external causes was unimportant, as expected. For ages 40-64, the decrease in Canadian male mortality rate ratios came from a decrease in rate ratios in the diseases of the heart and cerebrovascular diseases. For this group, there was a large decrease (43 and $36 \%$ ) in mortality rate ratios due to ischaemic and cerebrovascular diseases during the 1980-1995 period for men and women (Statistique Canada, 1998). So it seems that Canadian men in the 40-64 age group outperformed the men in other developed countries.

The situation was similar for the 65-79 group, but an increase in rate ratios for other causes counterbalanced the improvement in circulatory diseases, causing a small deterioration of the Canadian standing.

Among the elderly aged 80 and over, changes in cause-specific rate ratios actually favoured an improving Canadian position for women but not for men. The major fact here was the offset of the decreasing rates ratios for many causes, particularly for the two components of circulatory diseases, by an increase in rate ratios for the residual category (all other causes). As the residual category's share of total deaths declined during the period, it contributed less to changes in the rate ratios for total mortality. 
Robert Bourbeau

\section{Where Does Canadian Mortality Stand?}

To summarise the results presented above and suggest an interpretation, we can consider the following table (table 9) which shows the Canadian relative standing for each group of causes of death in the 1950s and in the mid 1990s as

well as the trends (up $\uparrow$, down $\downarrow$ or flat $\rightarrow$ ) for each group during the 19501995 period.

In the 1950s, mortality for some causes was above the average in the other developed countries (upper part of the table) but some of them had moved to the below average category by the end of the period. Mortality for other causes was below the average in the 1950s (lower part of the table) and some had moved above the average by the mid 1990s.

So, we can identify the causes of death that have moved above or below the average and for which the trend is upward, downward or flat.

The causes of deaths in the upper left cell are the constant threats to the Canadian relative position: diseases of the heart above age 40 (with a downward trend), cancers above age 65 , but with a downward trend above age 80 , motor vehicle accidents below age 15, and other accidents for ages 1 to 64 . Canadian women's mortality standing above age 40 is a concern, since mortality rates due to malignant tumors of the respiratory system more than doubled between 1976 and 1995. This rapid rise may be attributed for the most part to the increase of smoking among women since the 1950s (Statistics Canada, 1999).

The causes of deaths in the lower left cell are the emerging threats, i.e. the causes for which there was an increase in mortality rate ratios: suicide below age 40 , infectious diseases for age group 15-24, respiratory diseases for ages 65-79, digestive disorders below age 25 , residual causes for infants and adults above age 40 , and homicide.

The causes in the upper right cell are the receding threats: motor vehicle accidents above age 15, diseases of the heart for 25-39 and above age 80, cancers below age 40, and other accidents for infants and elderly above age 65 .

In the lower left cell, there are the causes for which the rate ratios were below the average and that are still below. Those, which show an upward trend, are possible threats to the relative status of Canadian mortality: respiratory, infectious, digestive diseases and residual causes.

Focussing on the oldest-old $(80+)$ for which the Canadian mortality rates were lower than in most of the countries included in the aggregate, the situation remains favourable but some changes may occur. Mortality rate ratios for all types of cancers were still above the average, but the trend was downward. Diseases of the heart and other accidents moved to the below-average category, 
Canadian Mortality in Perspective: A Comparison with the United States and other Developed Countries

Table 9

Relative Ranking of Canadian Mortality in the 1950s and in the 1990s, and Trends for the 1950-1995 Period (without USA in the aggregate)

\begin{tabular}{|c|c|c|}
\hline \multirow{2}{*}{$\begin{array}{l}\text { Canadian Mortality } \\
\text { in the } 1950 \mathrm{~s}\end{array}$} & \multicolumn{2}{|c|}{ Canadian Mortality in the Mid-1950s } \\
\hline & Above Average & Below Average \\
\hline Above Average & $\begin{array}{l}\text { Diseases of the Heart (40-79) } \\
\text { Cancers (65-79) } \\
\text { Motor Vehicle }(0-14) \\
\text { Other Accidents (1-39) } \longrightarrow \text { (40-64) } \\
\text { CONSTANT THREATS }\end{array}$ & $\begin{array}{l}\text { Motor Vehicle Accidents } \\
\text { Diseases of Heart }(25-39,80+) \\
\text { Cancers }(1-39) \\
\text { Other Accidents }(0,65+)\end{array}$ \\
\hline Below Average & $\begin{array}{l}\text { Suicide (1-39) } \\
\text { Infectiious (15-24) } \\
\text { Respiratory (65- 79) } \\
\text { Residual Causes (0,40+) (0-24) } \\
\text { Homocide }\end{array}$ & $\begin{array}{l}\text { Respiratory }(0-64,80+) \\
\text { Cerebrovascular } \\
\text { Diseases of Heart (1-24) } \\
\text { Digestive (25+) } \\
\text { Residual Causes (1-39) } \\
\text { Possidectious (1-14, 25+) }\end{array}$ \\
\hline
\end{tabular}


Robert Bourbeau

with also a downward trend. Residual causes (all other causes) moved to the above average category. Canadian mortality remained below the average for the other causes of death, but respiratory, infectious and digestive diseases were showing trends that could lead to some possible deterioration in the relative standing of the oldest-old.

As it is the case for the United States (Wilmoth, 1998), oldest-old men in Canada already experienced an increase in their mortality rate ratios over time. However, the mortality rate ratios were still lower at ages $80+(89$ for females and 92 for males) than for the other age groups (table $4 a$ ).

\section{What can Explain the Low Canadian Mortality Rates among the Oldest-Old: Some Hypotheses?}

The relatively low mortality among the $80+$ is a main feature of Canadian mortality, although it does not appear to be as surprising as in the US. But it needs explanation.

Many hypotheses have been raised to explain the relatively low mortality rates at older ages for the United States: data quality (exaggeration of age at death) (Coale and Kisker, 1986, 1990; Elo and Preston, 1994; Kannisto et al., 1994); population undercoverage for young age groups; excessive rates of mortality for adolescents and young adults due to accidents and violence; adverse selection (Manton and Vaupel, 1995; Vaupel, Manton and Stallard, 1979); socio-economic inequalities; existence of a universal medical care for the elderly (Himes, 1994; Bennett and Olshansky, 1996; Wilmoth, 1998).

Some hypotheses have been discarded or challenged by new findings (Wilmoth 1998; Hill et al. 2000). Other hypotheses are not adequate for Canada since they are founded on the existence of a higher relative mortality below age 65 (population undercoverage for young age groups; excessive rates of mortality for adolescents and young adults due to accidents and violence). We focus here on those hypotheses that can hold for Canadian mortality.

\section{Data Quality}

Less accurate data for the oldest-old, especially exaggeration of age at death, has been put forward as one of the familiar explanations for the lower mortality level in the US. However, recent findings from a record linkage study suggest that the data are reliable, at least for white Americans (Hill et al. 2000).

Data quality is also a concern for Canada, in particular at very old ages. In this study, mortality data were only available for a large open age-group: $80+$ in the WHO mortality database, and $90+$ in the Canadian mortality database (Statistics 
Canadian Mortality in Perspective:

A Comparison with the United States and other Developed Countries

Canada). Based on these data, it is difficult to draw any definite conclusion about the real trend in mortality at very old ages. According to our recent study (Bourbeau and Lebel, 2000), the Canadian data are quite good for ages 80 to 99 , and the main problems (exaggeration of age at death, misreporting of age at census) concern the centenarians. So the lower mortality for the $80+$ cannot be only explained as the product of bad data. However, more research must be done in Canada to investigate this problem. A matching study between Canadian social security and/or heath care files, and vital statistics and census figures would be appropriate.

\section{Selection Processes}

Another possible explanation for the lower mortality above age 80 is that survivors to these ages are a select group of individuals (Bennett and Olshansky, 1996, Wilmoth, 1998). These individuals are more wealthy, more educated and healthier, and they also can benefit from the programs providing medical care. This selection process may be associated with many phenomena but two of them appear highly plausible in the Canadian context: socio-economic inequalities and immigration.

Socio-economic inequalities

Although socio-economic inequalities are less severe in Canada than in the United States, many studies have identified mortality differentials in Canada according to social class, income, education, region of residence, ethnic or linguistic group, etc. (Wigle and Mao, 1980; Wilkins and Adams, 1983; Wilkins, Adams and Brancker, 1989; Choinière, 1993; Nault, 1997; Wilkins, 1995). According to House et al. (1990), excess morbidity and functional limitations prior to age 75 are concentrated in the lower socio-economic groups; moreover, the effect of socio-economic disparities on mortality differentials is greatest in the middle years of life and smaller at older ages. Differentials in mortality contribute to this selection process where as age increases the survivors are relatively healthier.

\section{The healthy immigrant effect}

Another hypothesis, probably the most interesting, concerns the selection induced by immigration. Canada has been a receiving country for a long time; the rate of immigration (7.5 immigrants per 1000 population) is currently one of the highest in the world (the rate for US and for Australia is 3.4 and 5.1, respectively). According the 1996 Canadian census, $18 \%$ of Canadians were born abroad; this percentage increases with age, reaching $34 \%$ for the $85-89$ years old and $43 \%$ above age 90 (This is partly due to the high levels of immigration at the beginning of the twentieth century).

Since migration is selective of healthy persons, immigrants should constitute a relatively healthy subset of the population. Many studies have shown evidence that 
the "healthy immigrant effect" observed in other countries also prevails for Canada. This hypothesis has been suggested for a long time. In a paper published in 1970 in Population, titled "Les plus faibles mortalités" ("The lowest mortality rates"), Nizard and Vallin have constructed the "best" life table (table des meilleurs quotients) by regrouping the lowest probabilities of dying observed in a country at the time (in the sixties) for each age and sex. Of course, most of the lowest probabilities were found in Norway, Sweden and Netherlands, but for the older ages, Canada and the United States had the lowest levels over age 80. The authors suggested that a selection process could explain this phenomenon, through the immigration that was a major factor in the settlement of those two countries. Migration selects more healthy persons who will have a better chance to survive to ages where endogenous mortality is important. The hypothesis is well documented in receiving countries and especially in Canada (Trovato, 1985, 1993, 1998; Trovato and Clogg, 1992; Sharma et al. 1990; Chen et al, 1996a, 1996b).

The pattern and level of mortality for immigrants and the Canadian-born are not identical. Trovato (1993) has shown that immigrants enjoy an overall lower level of mortality than the Canadian-born, and that the advantage for the immigrants is largely concentrated in the years from age 10 through 64 . Moreover, the life expectancy at birth among immigrants in Canada is higher than the populations at origin and destination (Sharma et al. 1990), which is contrary to the hypothesis that migrants would have characteristics intermediate between the place of origin and the place of destination (Lee, 1966).

More recent studies have supported the previous results. Immigrants, particularly those from the non-European countries, are healthier than the Canadian-born population in terms of chronic conditions and disability (Chen et al. 1996a); immigrants also have a longer life expectancy at birth (from 2.7 to 6.7 years for males and from 1.4 to 5.4 years for females) and at age 65 (from 1 to 4 years for males and from 0.2 to 4.1 years for females) (Chen et al. 1996b; Bourbeau, 2001).

The ordinal ranking of countries showed that receiving countries have a very good standing for the oldest-old. In addition to Canada and the United States, Australia, England, and New Zealand were also among the best countries for mortality for the $80+$ age groups. Other studies have also pointed out this common feature of English speaking countries (Himes, 1994; Condran, Himes, and Preston, 1991).

\section{The Health Care Program}

The existence of a universal heath care program in Canada may explain the difference between Canadian and American mortality patterns (Ng, 1992). In the United States, most of the governmental funding for health care is focused on older persons $(65+)$ and on young children, to a lesser extent. The comparative study of mortality reduction in the two countries during the 1951-1996 period (in the first section of this paper) suggests that the health care program in Canada has played an 


\section{Canadian Mortality in Perspective: \\ A Comparison with the United States and other Developed Countries}

important role in the modification of the age pattern of Canadian mortality over time.

However, if this factor can explain some of the differences between Canadian and American age mortality pattern, it can not be proposed as an explanation for the differences with other developed countries without some thorough analysis of health care programs in these countries. For example, it is possible that medical practices in Canada or in the US focus more than in other countries, on interventions that extend the life length of persons already old, without consideration of their health status. This element should also be studied carefully before invoking this reason in the differences of mortality levels among the oldestold.

\section{Conclusions}

In this paper, the evolution of Canadian mortality during the second half of the twentieth century has been analysed and compared with mortality in the United States and in other developed countries. This comparative analysis is relevant to assess the existence of a North American mortality pattern that would fit for Canada as well as for the United States. This mortality profile would be characterised by relatively high death rates below age 65 and relatively low death rates above age 80, when compared to other developed countries. Using data from WHO mortality database for total and cause-specific mortality, we applied a decomposition method to explain the changes in mortality rate ratios during the 1950-1995 period.

\section{Some deterioration in Canadian relative standing}

Our findings show that, in comparison to other developed countries except the United States, Canada has experienced an increase in its mortality rate ratios over the 1950-1995 period, for all age groups, except men in ages 40-64 and women above age 80 . Increases in cause-specific mortality rate ratios are partly responsible for this increase, but the shift in the proportion of death by causes during the 19501995 period also contributed. However the increase experienced by Canada was much smaller than that experienced by the US.

\section{Evidence of a North American mortality pattern}

The Canadian mortality pattern is less unusual than the American pattern. The mortality rate ratios were more consistent for each age group, and the mortality rate ratio for the oldest-old was not clearly lower than for the other age groups, as it was the case for the US. Thus, there is no evidence that the North American mortality pattern, as described above, fits for Canada. In fact, Canadian mortality below age 65 was quite comparable to mortality in other developed countries. 
Robert Bourbeau

\section{Lower level of mortality among the oldest-old}

One of the characteristics of the North American mortality pattern is present however. There was a contrasting low mortality level for the oldest-old $(80+)$. The relatively low level persisted during the whole period covered by this study. However, the evolution of rate ratios for some causes of death may be a threat to this dominance. In fact, some countries, like Japan, France, Switzerland, and Iceland, are catching up.

National differences in mortality levels are getting smaller among the most developed countries. For example, infant mortality rates are getting so close that a very small change in the rate can produce a huge change in the ordinal rankings, as was the case for Canada in 1990 and in 1995. The same convergence may be observed for the oldest-old in the near future.

\section{Some explanations or hypotheses}

Some explanations are proposed for this feature of Canadian mortality: data quality, socio-economic inequalities, healthy immigrant effect, and health care program. Future research should focus on these explanations.

\section{Acknowledgments:}

This is a revised version of a paper delivered at the Annual Meeting of the Population Association of America, Los Angeles, March 23-25, 2000. Much of this study was done during my Visiting Scholarship at the Department of Demography, University of California, Berkeley. I am thankful to John Wilmoth for his useful comments. Thanks are also due to Frank Trovato and Barry Edmonston for their helpful suggestions. Data processing for this paper was performed with diligence by Aaron Gullickson. This research was supported by a grant from the Social Science and Humanities Research Council of Canada (410-97-1090) and by a grant from the U.S. National Institute on Aging (R01AG11552). 
Canadian Mortality in Perspective:

A Comparison with the United States and other Developed Countries

\section{End Notes:}

1. For Canada, population estimates used by WHO are not adjusted for net census undercount. This may lead to a very small overestimation of mortality rates.

2. The expression "relative mortality rates" is sometimes used to identify this metric.

3. That is, $p^{A g}(i)=\frac{D^{A g}(i)}{D^{A g}}=\frac{M^{A g}(i)}{M^{A g}}$.

4. The baseline comparison for the early 1950's was for a much poorer Europe and Japan, since these countries were still under food rationing and rebuilding its public health and sanitation infrastructure. The reader should be aware that these countries started, then, from a disadvantaged situation compared to Canada and the U.S.A. in the 1950's.

\section{References:}

Bah, S.M. and Rajulton, F. 1991. "Has Canadian Mortality Entered the Fourth Stage of the Epidemiologic Transition." Canadian Studies in Population 18 (2): 18-41.

Bennett, N. G. and S. J. Olshansky. 1996. "Forecasting US Age Structure and Future of Social Security : The Impact of Adjustments to Official Mortality Schedules." Population and Development Review 22 (4): 703-727.

Bourbeau, R. 2001. «La sélection d'immigrants en bonne santé explique-t-elle le profil particulier de la mortalité canadienne aux grands âges?», Paper presented to the XXIVth General Conference on Population (IUSSP), 1824 August 2001, Salvador, Bahia, Brasil.

Bourbeau, R. and A. Lebel. 2000. "Mortality Statistics for the Oldest-Old : An Evaluation of Canadian Data". Demographic Research (Journal published by the Max Planck Institute for Demographic Research), Vol. 2/2, 36 p. This paper can be accessed through the Internet at: www.demographicresearch.org .

Bourbeau, R. and J. Légaré. 2000. "La baisse de la mortalité au Québec au début du XXe siècle: les distorsions de la vision transversale”, in De l'usage des seuils. Structures par âge et âges de la vie, Cahiers des Annales de démographie historique, no 2, p.107-118 
Robert Bourbeau

Bourbeau, R., J. Légaré and V. Émond. New Birth Cohort Life Tables for Canada and Quebec, 1801-1991, Ottawa, Statistics Canada, Demography Division, Demographic Document no 3, Catalogue 91F0015MPE, September 1997, 94 pages. This document can be accessed through the Internet at: www.statcan.ca .

Bourbeau, R. 1993. “Analyse comparative de la mortalité violente dans les pays industrialisés et dans quelques pays en développement durant la période 1985-1989”, World Health Statistics Quarterly Review (WHO) 46 (1) : 433.

Chen, J., E. Ng and R. Wilkins 1996a. "The Health of Canada's Immigrants in 1994-95". Health Reports 7 (4): 33-45.

Chen, J., R. Wilkins and Ng, E. 1996b. "Health Expectancy by Immigrant Status, 1986 and 1991". Health Reports 8 (3): 29-37.

Choinière, R. 1993. "Les inégalités socio-économiques et culturelles de la mortalité à Montréal à la fin des années 1980". Cahiers québécois de démographie 22 (2): 339-362.

Coale, A. J. and E. E.Kisker. 1990. "Defect in Data on Old-Age Mortality in the United-States: New Procedure for calculating Mortality Schedules and Life Tables at the Highest Ages." Asian and Pacific Population Forum 4 (1): $1-31$.

Coale, A J. and E. E. Kisker. 1986. "Mortality Crossovers: Reality of Bad Data?" Population Studies 40: 389-401.

Condran G. A., C. L. Himes and S. H. Preston. 1991. "Old Age Mortality Patterns in Low Mortality Countries: An Evaluation of Population and Death Data at Advanced Ages, 1950 to Present." Population Bulletin of the United Nations 30: 23-60.

Das Gupta, P. (1993) Standardization and Decomposition of Rates: A User's Manuel, Washington, Bureau of the Census, U.S. Department of Commerce, Current Population Reports, Special Studies, P23-186.

Das Gupta, P. (1991) "Decomposition of the Difference Between two Rates and its Consistency When more than two Populations are Involved", Mathematical Population Studies 3(2): 105-125.

Elo, I.T. and S.H. Preston. 1994. "Estimating African-American mortality from inaccurate data." Demography 31 (3): 427-458. 
Canadian Mortality in Perspective:

A Comparison with the United States and other Developed Countries

Goss, S.C., A. Wade and F. Bell. 1998. "Historical and Projected Mortality for Mexico, Canada and the United States". North American Actuarial Journal 2 (4): 108-126.

Hill, M.E., S.H. Preston and I. Rosenwaike. 2000. “Age Reporting among White Americans Aged 85+: Results of a Record Linkage Study". Demography 37 (2): 175-186.

Himes, C. L. 1994. "Age Patterns of Mortality and Cause-of-Death Structures in Sweden, Japan, and the United States.” Demography 31 (4): 633-50.

House, J.S., R.C. Kessler, et al. 1990. “Age, socioeconomic status, and health”. The Milbank Quarterly 68 (3): 383-411.

Kannisto, V., J. Lauritsen, R. Thatcher and J. W. Vaupel. 1994. "Reductions in Mortality at Advanced Ages: Several Decades of Evidence from 27 Countries." Population and Development Review 20 (4): 793-810.

Lebel, A. 1999. Évolution de la mortalité canadienne aux âges avancés de 1951 à 1995. 1999, Montréal, Département de démographie, Université de Montréal, Mémoire de maîtrise.

Lee, E.S. 1966. "A theory of migration”, Demography 3:47-57.

Manton, K. G. and J. W. Vaupel 1995. "Survival After the Age of 80 in the United States, Sweden, France, England and Japan.”, The New England Journal of Medicine 333 (18):1232-1235.

Nagnur, D. 1986. Longevity and Historical Life Tables 1921-1981 (Abridged) Canada and Provinces. Ottawa, Statistics Canada, cat. 89-506.

Nagnur, D. and M. Nagrodski. 1990. "Epidemiologic Transition in the Context of Demographic Change: The Evolution of Canadian Mortality Pattern". Canadian Studies in Population 17 (1) : 1-24.

Nault, F. 1997. 'Narrowing mortality gaps, 1978 to 1995, Health Reports 9 (1): $35-41$.

Nizard, A. and J. Vallin 1970. "Les plus faibles mortalités". Population 25 (4): 847-874.

Ng, E. 1992. "Reductions in Age-Specific Mortality Among Children and Seniors in Canada and in the United States, 1971-1989". Health Reports 4 (4): 367-378. 
Robert Bourbeau

Omran, A. R. 1971. "The epidemiological transition: A theory of epidemiology of population change", Milbank Memorial Fund Quarterly 49: 509-538.

Preston, S.H., I.T. Elo, I. Rosenwaike, and M.E.Hill. 1996. "African-American mortality at older ages: Results of a matching study". Demography 33 (2): 193-209.

Sharma, R.D., M. Michalowski, and R.B.P. Verma. 1990. 'Mortality Differentials among Immigrant Populations in Canada". International Migration 28 (4): 443-450.

Statistics Canada, 1998. Report on the Demographic Situation in Canada 1997. Current Demographic Analysis, Ottawa, Demography Division, Catalogue no. 91-209-XPE.

Statistics Canada, 1999. Report on the Demographic Situation in Canada 19981999. Current Demographic Analysis, Ottawa, Demography Division, Catalogue no. 91-209-XPE.

Trovato, F. 1998. "Nativity, marital status and mortality in Canada". Canadian Review of Sociology and Anthropology 35 (1): 65-91.

Trovato, F. 1993. "Mortality differences by nativity during 1985-87". Canadian Studies in Population 20 (2): 207-223.

Trovato, F., and C.G. Clogg 1992. "General and cause-specific adult mortality among immigrants in Canada, 1971 and 1981". Canadian Studies in Population 19 (1): 47-80.

Trovato, F. 1985. "Mortality differences among Canada's indigenous and foreignborn populations, 1951-1971". Canadian Studies in Population 12 (1): 4980 .

Vaupel, J.W., K.G. Manton, and E. Stallard. 1979. "The impact of heterogeneity in individual frailty on the dynamics of mortality". Demography 16 (3): 439454.

Wigle, D.T., and Y. Mao. 1980. Mortality by income in Urban Canada. Non Communicable Disease Division, Laboratory Centre for Disease Control, Heath Protection Branch, Minister of National Health and Welfare, Ottawa.

Wilmoth, J. R. 1998. "American Mortality in International Perspective: the Evolution of relative rankings by age". Paper presented to the Annual Meeting of the Population Association of America, Chicago, April 1998. 
Canadian Mortality in Perspective: A Comparison with the United States and other Developed Countries

Wilkins, R. 1995. "Policy-Relevant Health Information: the Canadian Experience in assessing socio-economic differentials in mortality". In: Adult Mortality in Developed Countries: From Description to Explanation. Edited by Lopez, A., G. Caselli, and T. Valkonen, Clarendon Press: Oxford, pp. 307-326.

Wilkins, R., O. Adams, and A. Brancker. 1989. "Changes in mortality by income in urban Canada from 1971 to 1986". Health Reports 1 (2): 137174.

Wilkins, R., and O. Adams. 1983. "Health expectancy in Canada, late 1970s: demographic, regional and social dimensions". American Journal of Public Health 73 (9): 1073-1080. 